\title{
The proteases HtrA2/Omi and UCH-L1 regulate TNF-induced necroptosis
}

\author{
Justyna Sosna ${ }^{1 \dagger}$, Susann Voigt ${ }^{1 \dagger}$, Sabine Mathieu ${ }^{1}$, Dieter Kabelitz ${ }^{1}$, Ahmad Trad ${ }^{2}$, Ottmar Janssen ${ }^{1}$, \\ Catherine Meyer-Schwesinger ${ }^{3}$, Stefan Schütze ${ }^{1}$ and Dieter Adam ${ }^{1 *}$
}

\begin{abstract}
Background: In apoptosis, proteolysis by caspases is the primary mechanism for both initiation and execution of programmed cell death (PCD). In contrast, the impact of proteolysis on the regulation and execution of caspase-independent forms of PCD (programmed necrosis, necroptosis) is only marginally understood. Likewise, the identity of the involved proteases has remained largely obscure. Here, we have investigated the impact of proteases in TNF-induced necroptosis.
\end{abstract}

Results: The serine protease inhibitor TPKC protected from TNF-induced necroptosis in multiple murine and human cells systems whereas inhibitors of metalloproteinases or calpain/cysteine and cathepsin proteases had no effect. A screen for proteins labeled by a fluorescent TPCK derivative in necroptotic cells identified HtrA2/Omi (a serine protease previously implicated in PCD) as a promising candidate. Demonstrating its functional impact, pharmacological inhibition or genetic deletion of HtrA2/Omi protected from TNF-induced necroptosis. Unlike in apoptosis, HtrA2/Omi did not cleave another protease, ubiquitin C-terminal hydrolase (UCH-L1) during TNF-induced necroptosis, but rather induced monoubiquitination indicative for UCH-L1 activation. Correspondingly, pharmacologic or RNA interference-mediated inhibition of UCH-L1 protected from TNF-induced necroptosis. We found that UCH-L1 is a mediator of caspase-independent, non-apoptotic cell death also in diseased kidney podocytes by measuring cleavage of the protein PARP-1, caspase activity, cell death and cell morphology. Indicating a role of TNF in this process, podocytes with stably downregulated UCH-L1 proved resistant to TNF-induced necroptosis.

Conclusions: The proteases HtrA2/Omi and UCH-L1 represent two key components of TNF-induced necroptosis, validating the relevance of proteolysis not only for apoptosis, but also for caspase-independent PCD. Since UCH-L1 clearly contributes to the non-apoptotic death of podocytes, interference with the necroptotic properties of HtrA2/Omi and UCH-L1 may prove beneficial for the treatment of patients, e.g. in kidney failure.

Keywords: Tumor necrosis factor, Necroptosis, Programmed necrosis, Apoptosis, Proteases, HtrA2/Omi, UCH-L1, Kidney failure

\section{Background}

Cleavage of proteins by caspases is essential for the apoptotic elimination of unwanted or potentially harmful cells and thus for the survival and homeostasis of multicellular organisms [1]. Whereas apoptosis represents the primary route to programmed cell death (PCD) in most physiological settings, non-apoptotic, caspase-independent

\footnotetext{
* Correspondence: dadam@email.uni-kiel.de

†Equal contributors

'Institut für Immunologie, Christian-Albrechts-Universität zu Kiel, Michaelisstr. 5, 24105 Kiel, Germany

Full list of author information is available at the end of the article
}

forms of PCD have been discovered which can act as a backup mechanism to allow cell suicide under conditions where the caspase machinery is inhibited (e.g. in apoptosis-resistant tumor cells or after virus infection) $[2,3]$. As the main mode of caspase-independent PCD, programmed necrosis (also termed "necroptosis" when mediated by the kinases RIPK1 and RIPK3) has emerged as an important and physiologically relevant response in vital processes, e.g. the elimination of chondrocytes, virus infection, bacterial infection [4] or the homeostasis of $\mathrm{T}$ cell populations [5]. Moreover, programmed necrosis has been described to trigger pathophysiological

\section{() Biomed Central}


alterations such as neurodegeneration [6], $\beta$-cell elimination from pancreatic islets/development of diabetes, loss of hypertrophic cardiomyocytes during heart failure [7], Crohn's disease [8], acute pancreatitis, ischemic injury and inflammation $[4,9,10]$.

At the molecular level, the signaling pathways of programmed necrosis and necroptosis are still incompletely understood. The best studied model of programmed necrosis, necroptosis mediated by the $55 \mathrm{kDa}$ tumor necrosis factor (TNF) receptor (TNF-R1) depends on the activity of the kinases RIPK1 and RIPK3 and the protein MLKL. These essential core components relay the necroptotic signal to further downstream effectors such as PGAM5L/S and Drp-1, thereby inducing mitochondrial fragmentation [11]. Independently, production of reactive oxygen species, e.g. by mitochondria or by the NADPH oxidase Nox1, lipid peroxidation, enzymes of the energy metabolism, the deubiquitinase CYLD and the Bcl-2 family member Bmf have been suggested as further mediators of necroptosis [12]. In addition, our own group has previously identified the sphingolipid ceramide as a key effector of TNF-induced necroptosis [13,14]. Moreover, we have been able to show in a very recent study that, in contrast to previous assumptions [12], TNF-induced necroptosis is not mediated by the "PARP pathway" (a signaling cascade that involves overactivation of the DNA repair enzyme PARP-1, depletion of intracellular $\mathrm{NAD}^{+}$and ATP, release of apoptosis-inducing factor from mitochondria, DNA fragmentation and cell death). Rather, necroptosis induced by TNF and the PARP pathway represent two independent and distinct routes to programmed necrosis [15].

In contrast to apoptosis, which depends essentially on the proteolytic activity of caspases, the role of proteolytic events for both regulation and execution of necroptosis/ programmed necrosis is considerably less well characterized. Aside from a negative regulation of necroptosis by caspase- 8 via cleavage and inactivation of RIPK1 [3], lysosomal proteases such as cathepsin B, D, calpains, granzymes and cys-cathepsins can substitute for caspases in some, but not all forms of programmed necrosis [16]. Also, the endoplasmic reticulum (ER) can induce programmed necrosis in response to cellular stress or uncontrolled release of calcium through calpain proteases $[16,17]$. Several groups (including our own) have independently observed that serine protease inhibitors such as tosyl phenylalanyl chloromethyl ketone (TPCK) can inhibit both necroptosis/programmed necrosis [18-21] and apoptosis [22]. For apoptosis, serine proteases have been found to complement or augment the function of caspases, e.g. granzyme B can stimulate apoptosis by cleavage of several procaspases, the pro-apoptotic protein Bid, or inhibitor of caspase-activated DNAse (ICAD) in cytotoxic $\mathrm{T}$ lymphocytes and natural killer cells [22]. For necroptosis/programmed necrosis, the identity of the relevant serine proteases and that of their substrates has remained largely obscure.

Here, we have identified the serine protease HtrA2/Omi as a key protease that mediates TNF-induced necroptosis. HtrA2/Omi is the mammalian homologue of the bacterial $\mathrm{Htr}$ A endoprotease and highly conserved from bacteria to mammalians. In the latter, HtrA2/Omi is involved in the degradation of misfolded proteins during conditions of cellular stress (e.g. ER stress, heat shock and ischemia/ reperfusion) [23]. Deletion of $\mathrm{HtrA} 2 / \mathrm{Omi}$ or mutations affecting its activity have been associated with neurodegeneration and Parkinson's disease in mouse models [24] and patients [25]. In response to apoptotic stimuli, HtrA2/Omi is released from mitochondria into the cytoplasm, where it promotes apoptosis by binding and inhibiting IAP (inhibitor of apoptosis) proteins, thus releasing active caspases from their natural inhibitors. Independently, HtrA2/Omi degrades IAPs, the caspase- 8 inhibitor Pea-15 and the anti-apoptotic protein HAX-1 through its serine protease activity, further promoting apoptosis [25].

In contrast to apoptosis, the molecular details of how HtrA2/Omi participates in necroptotic signaling are largely unknown. It has been reported that HtrA2/Omi can mediate caspase-independent PCD via its serine protease activity, e.g. upon interleukin-3 deprivation of the mouse pro-B cell line Ba/F3 [25], in imatinib-treated human leukemic cells [26], or in cytomegalovirus infection [27]. However, except for one study reporting cleavage and inactivation of RIPK1 by HtrA2/Omi [25], the substrates of HtrA2/Omi in necroptosis/programmed necrosis are unknown.

In the course of this study, we have identified ubiquitin C-terminal hydrolase (UCH-L1) as a second protease which participates in TNF-induced necroptosis downstream of HtrA2/Omi. UCH-L1 belongs to the family of cysteine proteases and functions as a deubiquitinase which generates, binds and stabilizes ubiquitin monomers, and thus can replenish the cellular monoubiquitin pool. Independently, UCH-L1 may act as an ubiquitin ligase [28], and may even have functions independent of the ubiquitin-proteasome system [29]. UCH-L1 is mainly expressed in neuronal tissues (very abundantly in the brain), in synovial membranes and in cells of the testis, ovaries, and kidney $[28,30]$. Abnormal expression of UCHL1 is found in many forms of cancer, including lung, colorectal, and pancreatic cancers, and may be related to tumor progression [29]. Aberrant expression of UCH-L1 has also been associated with neurodegenerative diseases, ischemic and traumatic brain injury [31]. Accordingly, and similar to $\mathrm{HtrA} 2 / \mathrm{Omi}$, mutations in UCH-L1 have been associated with Parkinson's disease, as well as with other neurodegenerative disorders such 
as Alzheimer's disease [30,32]. De novo expression of $\mathrm{UCH}-\mathrm{L} 1$ is involved in podocyte injury and proteinuria in the kidney, possibly mediated through activation of the transcription factor NF- $\mathrm{kB}[30,31]$. However, the true in vivo functions as well as the physiological substrates of UCHL1 remain unclear at present [29].

In this study, we have investigated the role of proteases in the regulation of TNF-induced necroptosis and establish two non-caspase proteases, the serine protease $\mathrm{HtrA} 2 / \mathrm{Omi}$ and the deubiquitinase $\mathrm{UCH}-\mathrm{L} 1$ as regulators of this form of PCD, simultaneously identifying two novel potential targets for therapeutic intervention.

\section{Results}

Inhibition of serine proteases, but not metalloproteases, cathepsin or calpain/cysteine proteases protects from TNF-induced necroptosis

In a first set of experiments, we investigated the effects of different protease inhibitors on TNF-induced necroptosis. As shown in Figure 1A, TPCK, an inhibitor of chymotrypsin-like serine proteases significantly protected murine L929Ts fibrosarcoma cells (a tumor necrosis factor-related apoptosis-inducing ligand (TRAIL)-sensitive L929 subline derived in our laboratory [33]) from TNF-induced necroptosis, consistent with a previous study in parental L929 cells [21]. We found that TPKC also significantly diminished TNF-induced necroptosis in murine NIH3T3 fibroblasts cells as well as in human leukemic Jurkat T cells and in human HT-29 colorectal adenocarcinoma cells (Figure 1A) as further established cell systems for necroptosis [14,15,34]. We next investigated whether TNF-induced necroptosis is regulated by metalloproteinases. However, TAPI-1, an inhibitor of TACE (TNF- $\alpha$ converting enzyme, ADAM17) and other metalloproteinases, as well as GM 6001 and marimastat, two further broad-spectrum inhibitors of matrix metalloproteinases, had no inhibitory effect on TNF-induced necroptosis in L929Ts or NIH3T3 cells (Figure 1B). Likewise, inhibitors of the cysteine proteases cathepsin $\mathrm{B} / \mathrm{L}$ (zFA-fmk), cathepsin B (Ca-074 Me), cathepsin L (zFF-fmk), as well as the broad-spectrum calpain/cysteine protease inhibitor E-64 did not protect L929Ts cells from TNF-induced necroptosis (Figure 1C), in line with previous findings $[14,15,33]$. In summary, these results suggest that chymotrypsin-like serine proteases participate in TNF-induced necroptosis in a cell type- and species-independent manner whereas inhibition of metalloproteinases, cathepsins and calpain/cysteine proteases has no major impact in this form of PCD.

\section{A screen for serine proteases relevant in TNF-induced necroptosis reveals $\mathrm{HtrA2} / \mathrm{Omi}$ as a promising candidate} To identify the TPCK-sensitive serine protease(s) that regulate TNF-dependent necroptosis, we adapted an approach that had been previously employed to successfully identify proteases relevant for endoplasmic reticulum (ER) stress-induced caspase-independent PCD [35]. For this purpose, we induced necroptosis in L929Ts cells (to activate the relevant serine proteases) in the presence of a cell-permeable, active-site-directed, fluorescently labeled TPCK-derivative (FAM-FFCK), aiming to affinitylabel only the subset of serine proteases that are activated during TNF-induced necroptosis. Lysates from the cells were separated by two-dimensional (2D) gel electrophoresis, and labeled protein spots were analyzed by mass spectrometry. Out of the analyzed 128 protein spots, 80 could be identified with high ("confirmed") and 28 with lesser confidence ("candidate"). However, showing the limitations of this method and obviously due to a nonspecific background binding of FAM-FFCK, most of the 108 proteins turned out to be non-proteases. Nevertheless, the mitochondrial serine protease HtrA2/Omi was identified in this screen with high confidence (Figure 2), and we considered it as the most promising candidate, because it had been already associated with both caspasedependent as well as caspase-independent PCD [25].

\section{HtrA2/Omi mediates TNF-induced necroptosis}

To investigate whether HtrA2/Omi was indeed functionally involved in the execution of TNF-induced necroptosis, we performed a first set of experiments in which we blocked the serine protease activity of HtrA2/ Omi with the specific inhibitor Ucf-101 [36]. As shown in Figure 3A, treatment with Ucf-101 uniformly protected L929Ts, HT-29 and Jurkat I42 (a FADDdeficient, TNF-R2-transfected Jurkat subline which rapidly undergoes necroptosis in response to TNF [37]) cells from TNF-induced necroptosis, strongly suggesting that the serine protease activity of $\mathrm{HtrA} 2 / \mathrm{Omi}$ is required for this process. Notably, incubation of L929Ts cells with Ucf-101 in combination with TPCK did not confer a stronger protection from necroptosis than the individual application of each inhibitor (Figure 3B), suggesting that both inhibitors do not act in an additive manner but rather via the same signaling pathway or even the same target (i.e. HtrA2/ Omi). However, since results obtained with pharmacological inhibitors should be interpreted with a certain caution due to their potential nonspecific effects, we sought to further substantiate the function of $\mathrm{HtrA} 2 / \mathrm{Omi}$ in TNF-induced necroptosis by selectively targeting its expression using RNA interference. As shown in Figure 3C, transfection of murine L929Ts or human Jurkat I42 cells with the corresponding siRNAs clearly downregulated the expression of HtrA2/Omi (although not completely). However, we did not detect a corresponding inhibition of TNF-induced necroptosis; i.e. loss of intracellular ATP measured as a marker for cell death was not prevented by HtrA2/Omi-specific siRNAs relative to a negative control 


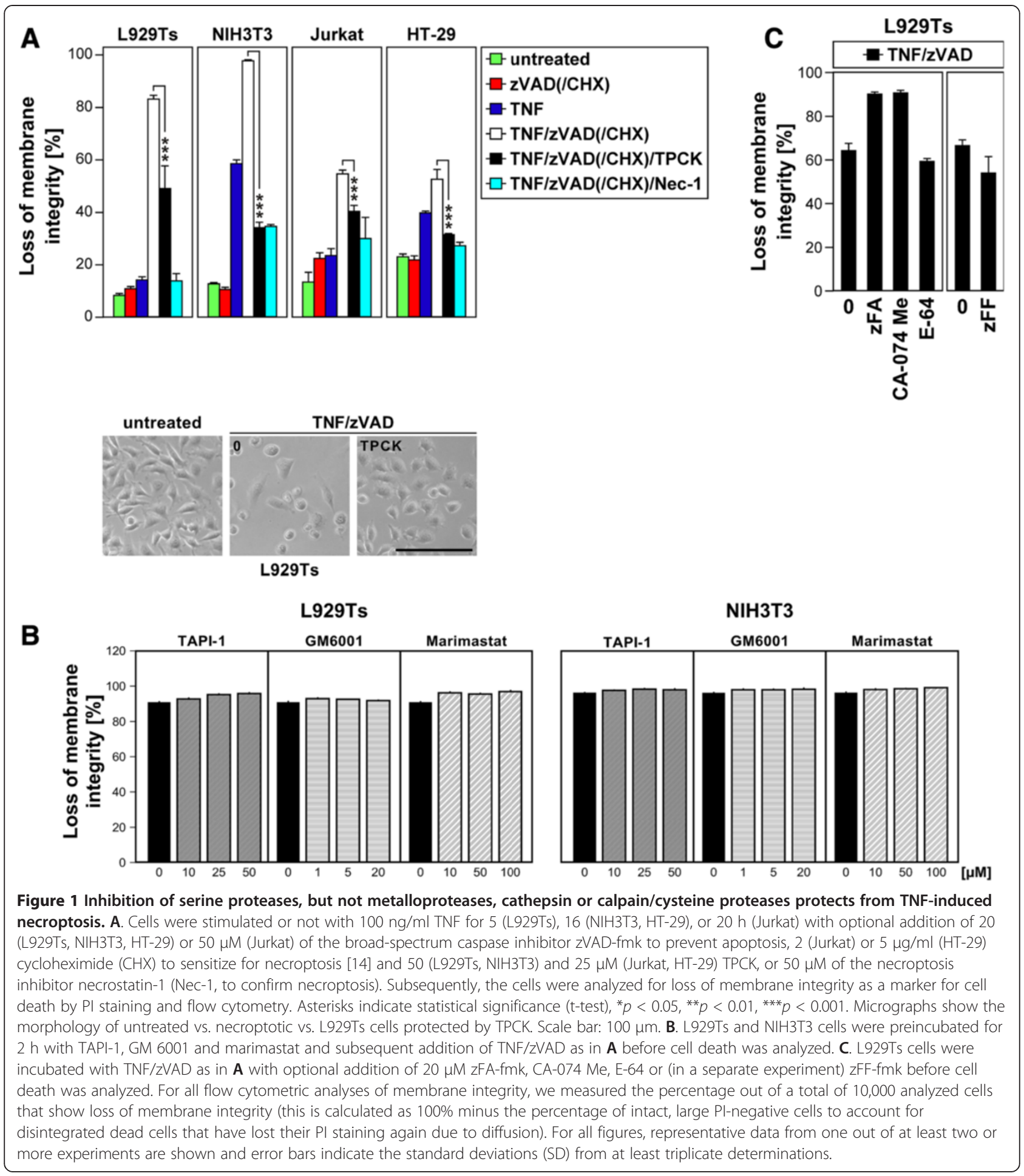

siRNA (Figure 3C). As one possible explanation for this result, the achieved reduction of HtrA2/Omi expression (and thus activity) might not yet be sufficient to inhibit the death response. Alternatively, this result might indicate lack of a role for HtrA2/Omi in TNF-induced necroptosis and leave the possibility that cell death is mediated by TPCK-sensitive serine proteases other than HtrA2/Omi. Regardless of either interpretation, these results were not consistent with the data obtained by pharmacological inhibition with Ucf-101. To resolve this discrepancy, we obtained and analyzed mouse embryonic fibroblasts (MEF) from HtrA2/Omi-deficient mice in a 


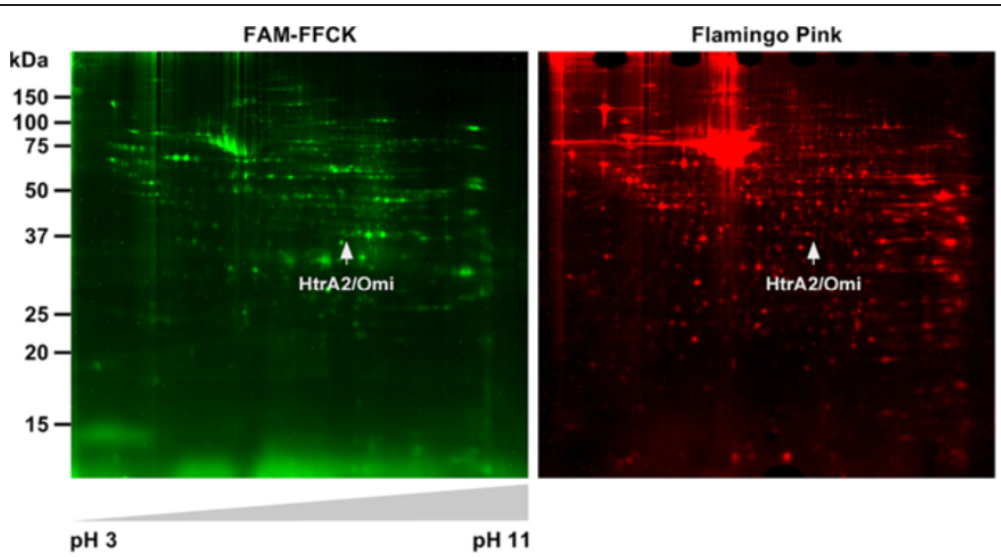

Figure 2 Identification of HtrA2/Omi as a candidate serine protease involved in necroptosis. L929Ts cells were stimulated with $100 \mathrm{ng} / \mathrm{ml}$ TNF for $5 \mathrm{~h}$ in combination with $20 \mu \mathrm{M}$ zVAD-fmk, $2 \mu \mathrm{g} / \mathrm{ml}$ CHX (to enhance necroptosis) and $50 \mu \mathrm{M}$ FAM-FFCK. Subsequently, lysates from the cells were separated by 2D gel electrophoresis and analyzed for protein spots labeled by FAM-FFCK (left panel, green), or for the total of all separated protein spots by staining with Flamingo Pink (right panel, red). The protein spot subsequently identified by mass spectrometry as HtrA2/Omi is indicated by arrows.

direct genetic approach. As demonstrated previously [24], and as shown in Figure 3D, these cells are completely devoid of any residual HtrA2/Omi protein (and thus activity). In assays for TNF-induced necroptosis, HtrA2/Omideficient cells were fully protected (Figure 3D), confirming the results with Ucf-101 and in summary validating that HtrA2/Omi is a key mediator of TNF-induced necroptosis.

\section{HtrA2/Omi induces monoubiquitination rather than cleavage of its substrate UCH-L1 during TNF-induced necroptosis}

The above results demonstrated that the protease activity of HtrA2/Omi is required for the necroptotic response to TNF, suggesting that necroptosis is relayed by proteolysis of HtrA2/Omi substrates. Since a previous study had shown that UCH-L1 is cleaved by HtrA2/Omi during staurosporine-induced apoptosis [38], we investigated whether $\mathrm{UCH}-\mathrm{L} 1$ also served as a substrate and thus potential downstream effector of $\mathrm{HtrA} / \mathrm{Omi}$ in TNF-induced necroptosis. Initially supporting this assumption, Western blots revealed a decrease of the $25-\mathrm{kDa}$ band representing full-length $\mathrm{UCH}-\mathrm{L}$ in lysates from wild-type (WT) MEF after induction of necroptosis by TNF/zVAD/CHX (but not in untreated or zVAD/ CHX-treated controls, Figure 4A). Moreover, this decrease was not detectable in HtrA2/Omi-deficient MEF (Figure $4 \mathrm{~A}$ ), and is therefore caused by $\mathrm{HtrA} 2 / \mathrm{Omi}$ in the course of necroptosis. In addition, HtrA2/Omideficient MEF showed higher basal levels of UCH-L1 (Figure 4A), suggesting a constitutive negative impact of HtrA2/Omi on the levels of UCH-L1 in WT MEF. Since the monoclonal UCH-L1 antibody utilized in this experiment recognized only the full-length $25-\mathrm{kDa}$ form of $\mathrm{UCH}-\mathrm{L} 1$, we incubated a parallel blot with a polyclonal antibody for UCH-L1 to visualize additional cleavage fragments. As shown in Figure 4A, this antibody indeed detected a smaller band at $15 \mathrm{kDa}$. However, this band was uniformly present in WT and HtrA2/Omi-deficient MEF. Moreover, it did not increase but rather decreased upon induction of necroptosis in WT MEF (showing the same intensity pattern as full-length UCH-L1). Therefore, the $15-\mathrm{kDa}$ band most likely represents a cleavage fragment of UCH-L1 which is constitutively generated by a protease distinct from $\mathrm{HtrA} 2 / \mathrm{Omi}$, and independent from necroptosis.

Park and colleagues have reported that HtrA2/Omi cleaves UCH-L1 during staurosporine-induced apoptosis, generating a $10-\mathrm{kDa}$ cleavage fragment (although this was shown only in vitro and upon overexpression, but not for the endogenous proteins) [38]. We therefore included positive controls for cleavage of endogenous UCH-L1 by endogenous HtrA2/Omi by treating WT MEF with staurosporine, and additionally compared them to staurosporine-treated HtrA2/Omi-deficient MEF. Furthermore, we employed gel systems that specifically resolve low molecular weight fragments to detect any cleavage fragments that might have been missed in the experiment shown in Figure 4A. In line with the observations by Park and colleagues (but now shown for the first time for endogenous UCH-L1), we detected a very faint $\mathrm{UCH}-\mathrm{L} 1$ cleavage fragment of $10 \mathrm{kDa}$ in lysates from staurosporine-treated WT MEF. As an explanation for the low intensity of the $10-\mathrm{kDa}$ fragment, Park and colleagues had previously been unable to detect endogenous cleavage fragments in WT MEF altogether (only in vitro and in overexpression systems), and had attributed this to an enhanced susceptibility of these fragments to degradation [38]. Nevertheless, the presence of this fragment in 


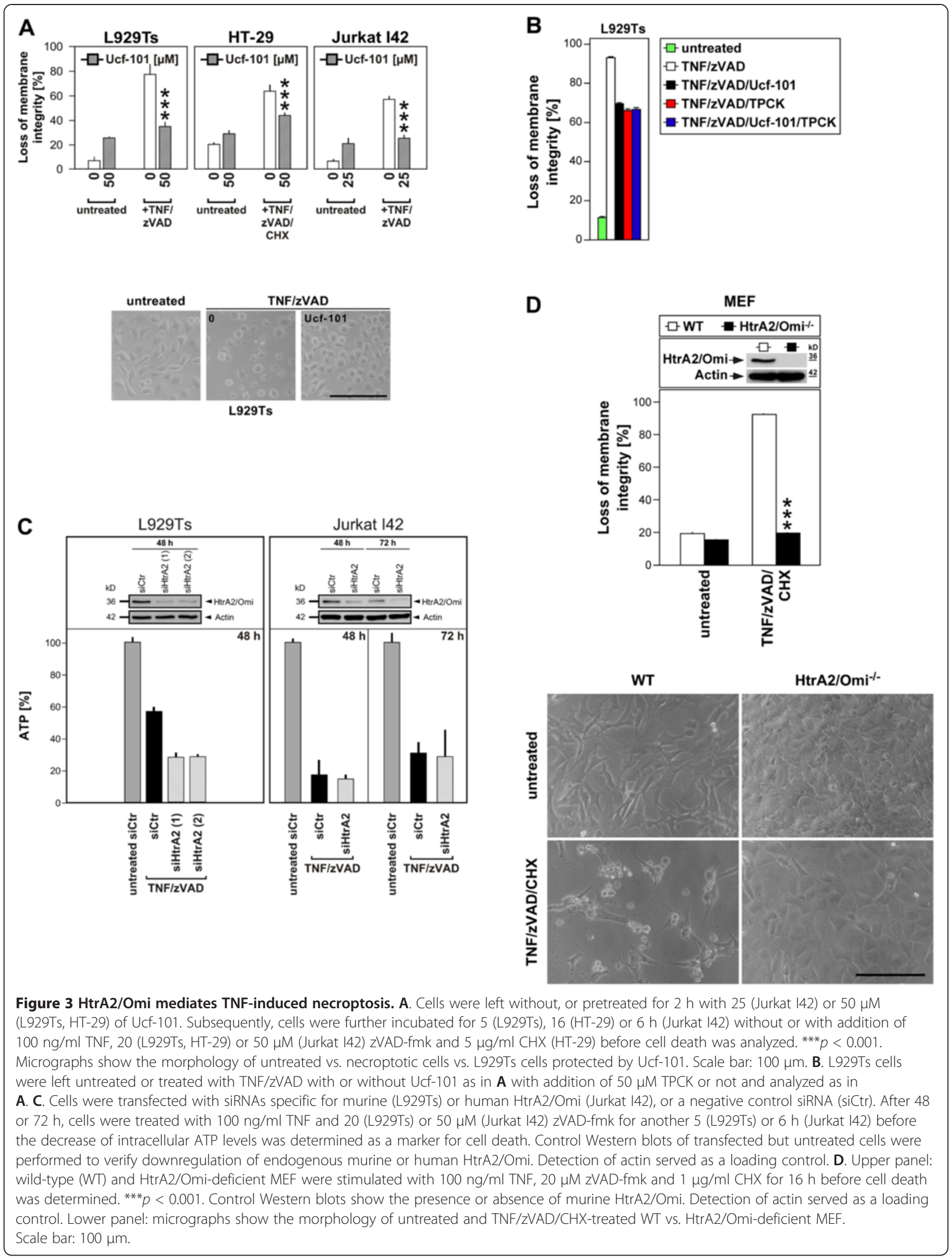




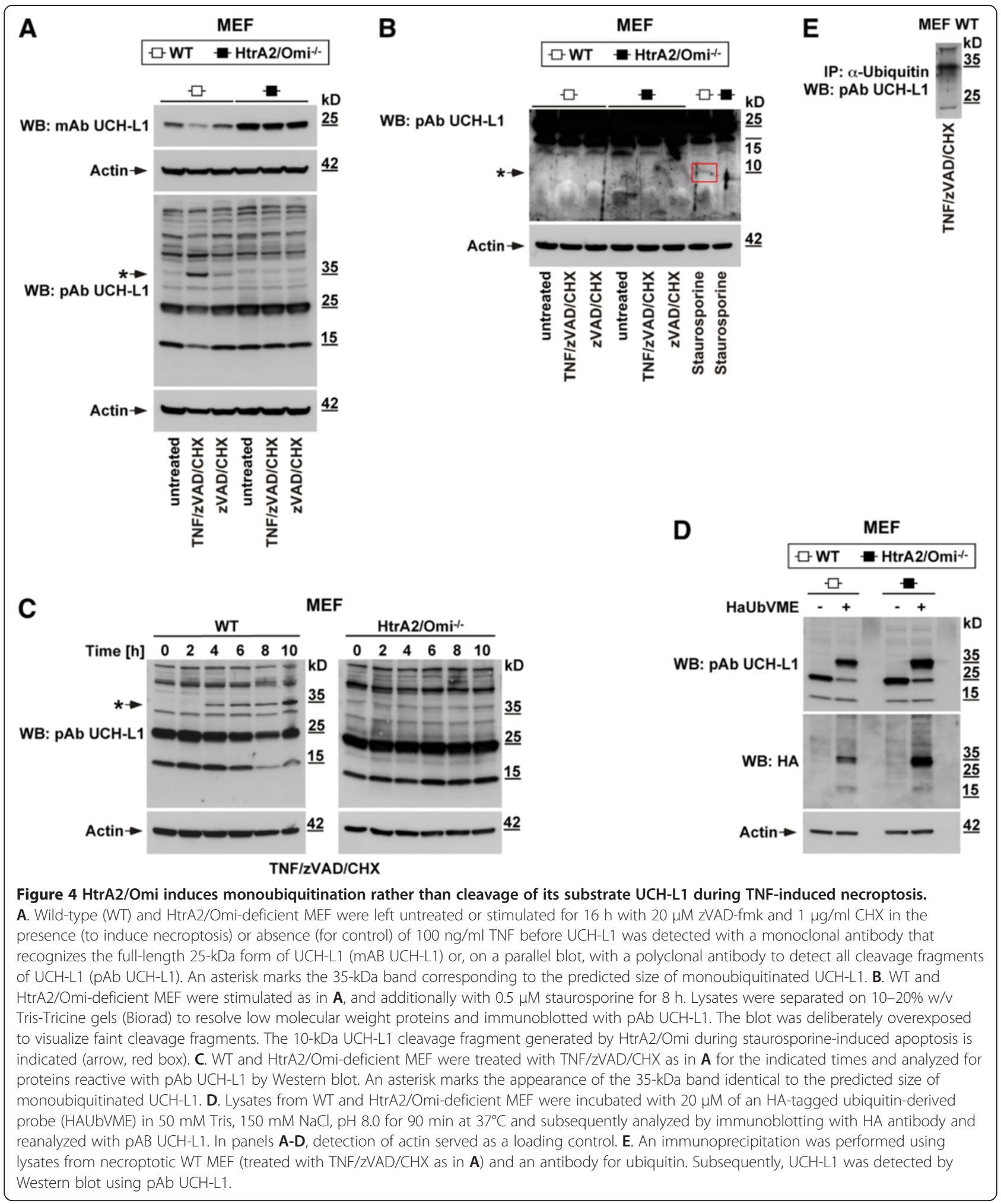

staurosporine-treated WT but not in HtrA2/Omi-deficient MEF (Figure 4B) confirmed that UCH-L1 is cleaved by $\mathrm{HtrA} 2 / \mathrm{Omi}$ in staurosporine-induced apoptosis. In contrast, the $10-\mathrm{kDa}$ fragment was clearly absent in all lysates from both WT and HtrA2/Omi-deficient MEF analyzed for TNF-induced necroptosis as well as the accompanying controls (Figure 4B). Given these results, we considered it unlikely that the observed decrease of the 
25-kDa full-length UCH-L1 band in necroptotic WT MEF was resulting from a direct proteolytic cleavage of UCH-L1 by HtrA2/Omi.

Searching for an alternative explanation, we noticed that the disappearance of the $25-\mathrm{kDa} \mathrm{UCH}-\mathrm{L} 1$ band during TNF-induced necroptosis was accompanied by the concurrent appearance of a prominent band of $\sim 35 \mathrm{kDa}$ (Figure $4 \mathrm{~A}$ ). Like the $25-\mathrm{kDa}$ band, this band was completely absent in HtrA2/Omi-deficient as well as in untreated WT MEF (and only very faintly detectable as a background band in control WT MEF treated with zVAD/CHX). To obtain further insight, we extended the above analysis in a timecourse experiment. As shown in Figure $4 \mathrm{C}$, induction of necroptosis in WT MEF by TNF/ zVAD/CHX caused the appearance of the $\sim 35-\mathrm{kDa}$ band within $4 \mathrm{~h}$ of treatment and again reduced the levels of the 25-kDa UCH-L1 form (most clearly visible after $8 \mathrm{~h}$ ). Again, this was not detectable in HtrA2/Omi-deficient MEF (Figure 4C), in line with the results shown in Figure $4 \mathrm{~A}$, and once more demonstrating that these changes are mediated by HtrA2/Omi. Interestingly, a band of $\sim 35 \mathrm{kDa}$ reactive with $\mathrm{UCH}-\mathrm{L} 1$ antibodies has also been described by other groups, and has been suggested to represent a monoubiquitinated form of UCH-L1 $[29,32,39]$. To clarify whether this was the case, we incubated lysates from WT and HtrA2/Omi-deficient MEF with an ubiquitin-derived probe tagged to hemagglutinin (HA) that covalently binds to deubiquitinating enzymes such as UCH-L1 [32]. In Western blots for UCH-L1, incubation of the lysates with this probe caused a shift of the full-length UCH-L1 band from $25 \mathrm{kDa}$ to $\sim 35 \mathrm{kDa}$. Moreover, an antibody against the HA tag of the probe selectively reacted with this $\sim 35-\mathrm{kDa}$ band (Figure $4 \mathrm{D}$ ). We additionally immunoprecipitated ubiquitinated proteins from WT MEF after induction of necroptosis with TNF/ zVAD/CHX and performed Western blots for UCH-L1, again detecting a band at $\sim 35 \mathrm{kDa}$ (Figure $4 \mathrm{E}$ ). In summary, these results confirm that the size shift from $25 \mathrm{kDa}$ to $\sim 35 \mathrm{kDa}$ is indeed caused by monoubiquitination of $\mathrm{UCH}-\mathrm{L} 1$. It is noteworthy that two of the above groups have independently shown that this modification leads to activation of UCH-L1 [29,32], prompting us to investigate the functional relevance of UCH-L1 activity for TNFmediated necroptosis in the next set of experiments.

\section{Inhibition of UCH-L1 protects from TNF-induced necroptosis}

For this purpose, we employed LDN57444, a previously described active site-directed inhibitor which specifically targets the enzymatic activity of UCH-L1 [40]. As shown in Figure 5A, treatment of L929Ts cells with LDN57444 significantly protected from TNF-mediated necroptosis. To exclude that this was due to nonspecific effects of this pharmacological inhibitor, we additionally downregulated UCH-L1 by RNA interference, measuring loss of intracellular ATP as a marker for TNF/ zVAD-induced necroptosis. Compared to L929Ts cells transfected with a negative control siRNA, transfection with an siRNA specific for UCH-L1 significantly inhibited loss of ATP, almost as effective as transfection with an siRNA specific for RIPK3, which we used as a positive control to validate the assay (Figure 5B). In summary, the above results support the hypothesis that $\mathrm{UCH}-\mathrm{L} 1$ is not cleaved by, but rather indirectly activated downstream of $\mathrm{HtrA} 2 / \mathrm{Omi}$, further relaying the necroptotic signals elicited by TNF.

\section{UCH-L1 is a mediator of caspase-independent,} non-apoptotic cell death in diseased kidney podocytes

Remarkably, UCH-L1 has also been associated with increased cell death in patients with kidney failure. In particular, de novo expression and thus increased UCHL1 activity in kidney podocytes was found in specific, mostly irreversible forms of glomerular injury in patients, rats and mice and is apparently responsible for disease aggravation in experimental models of membranous nephropathy [30,31]. Accordingly, inhibition of UCH-L1 with LDN57444 diminished kidney damage in these models whereas overexpression of UCH-L1 enhanced podocyte destruction. At present, it is however completely unclear whether death of podocytes in response to increased UCH-L1 activity is mediated by apoptosis, by autophagic mechanisms, by necroptosis or other forms of programmed necrosis. For apoptosis, evidence for podocyte death is scarce, suggesting that apoptosis is not a general pathway of podocyte loss in vivo [41]. As a second potential mode of PCD, autophagy has rather been associated with a healthy and differentiated status of podocytes, implicating that podocyte autophagy is a protective instead of pro-death pathway in glomerular disease [41]. Finally, necroptosis in podocytes has been investigated so far in only one study, where healthy podocytes (which do not express UCH-L1 [28]) proved resistant to both necroptosis and apoptosis [42].

To explore the mode of cell death that podocytes undergo in response to an increase in UCH-L1 expression/activity, we utilized murine podocytes stably transduced with a doxycycline-inducible overexpression construct for UCH-L1 (UCH-L1 tet-on podocytes). In a first approach, we investigated cell death in untreated and doxycycline-treated UCH-L1 tet-on podocytes directly. As shown in Figure 6A, cell death in untreated UCH-L1 tet-on podocytes was negligible whereas induction of $\mathrm{UCH}-\mathrm{L} 1$ expression by doxycycline significantly increased the numbers of dying podocytes (thereby also demonstrating the functionality of the system). More importantly, the addition of zVAD-fmk as a broad-spectrum inhibitor of caspases and thus of apoptosis did not inhibit but rather 

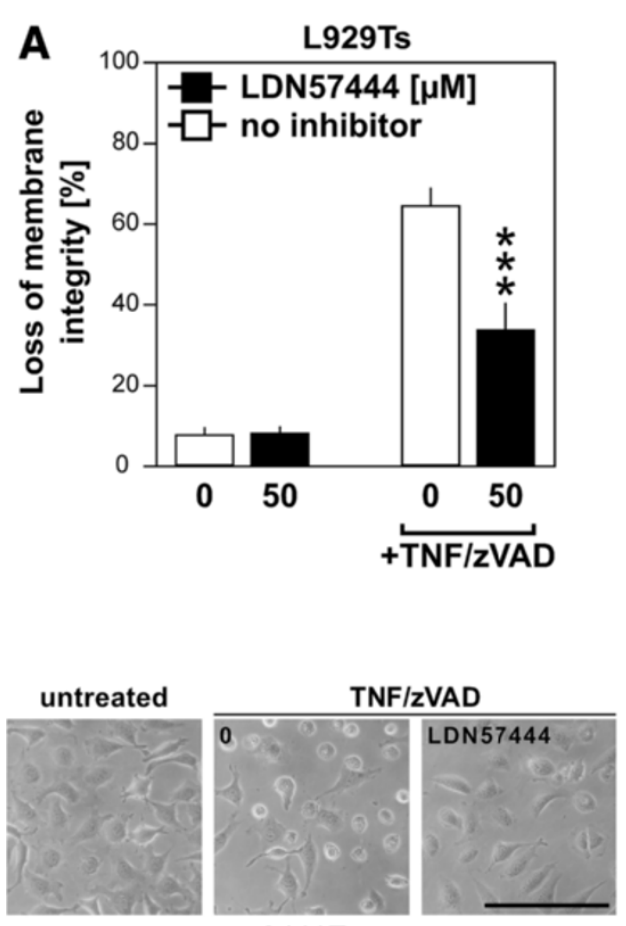

L929Ts

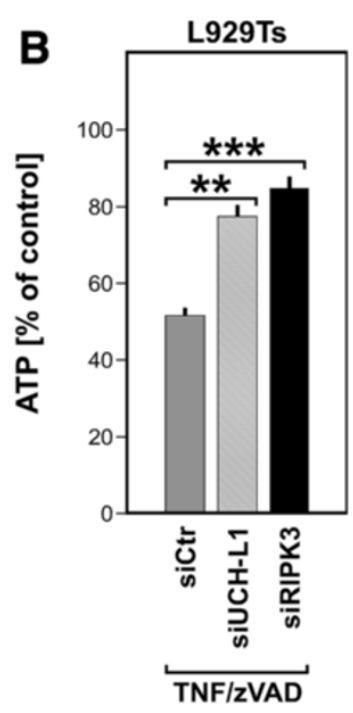

Figure 5 Inhibition of UCH-L1 protects from TNF-induced necroptosis. A. L929Ts cells were prestimulated for $3 \mathrm{~h}$ with $50 \mu \mathrm{M}$ of the UCH-L1 inhibitor LDN57444 or left unstimulated before addition of $100 \mathrm{ng} / \mathrm{ml}$ TNF and $20 \mu \mathrm{M}$ zVAD-fmk for $5 \mathrm{~h}$. Subsequently, cell death was analyzed by PI staining and flow cytometry. Asterisks indicate statistical significance (t-test), ${ }^{* *} p<0.001$. Micrographs additionally show the morphology of untreated L929Ts cells vs. necroptotic cells vs. cells protected by LDN57444. Scale bar: $100 \mu \mathrm{m}$. B. L929Ts cells were transfected with an siRNA that does not elicit an RNAi response (negative control, siCtr), with an siRNA specific for murine UCH-L1, and with an siRNA specific for murine RIPK3 (positive control for protection from necroptosis, siRIPK3) as described in "Methods." $48 \mathrm{~h}$ after transfection, cells were treated with $100 \mathrm{ng} / \mathrm{ml}$ TNF and $20 \mu \mathrm{M}$ zVAD-fmk for another $5 \mathrm{~h}$ before the decrease of intracellular ATP levels was determined as a marker for cell death. ATP levels are shown relative to controls that were not treated with TNF/zVAD. Asterisks indicate statistical significance $\left(\mathrm{t}\right.$-test), ${ }^{* *} p<0.01$, ${ }^{* * *} p<0.001$.

enhanced UCH-L1-dependent cell death. We and others have previously observed this effect of zVAD-fmk in necroptosis $[14,33,43]$, excluding that de novo expression and thus increased UCH-L1 activity causes death of podocytes by apoptosis but rather pointing to programmed necrosis/necroptosis as the responsible suicide program.

To extend these results, we investigated cleavage of PARP-1, a DNA-associating repair enzyme which is inactivated in apoptosis by caspase-3-dependent processing of the mature $116-\mathrm{kDa}$ protein to an $89-\mathrm{kDa}$ cleavage product [44]. When we analyzed lysates from UCH-L1 tet-on podocytes treated with doxycycline for $72 \mathrm{~h}$ or not in Western blots, the full-length $116-\mathrm{kDa}$ PARP-1 band was uniformly visible in all samples, together with a pattern of additional bands. However, this pattern did not change upon treatment with doxycycline (Figure 6B). In particular, the characteristic disappearance of the full-length 116-kDa PARP-1 band as well as the corresponding increase of the $89-\mathrm{kDa}$ cleavage fragment that we have previously observed for apoptosis in multiple studies $[13,15,33]$, and which is also shown for control in L929Ts cells (Figure 6B) could not be detected. Given that caspase-3 acts downstream of all other apoptotic caspases as the central effector caspase of both extrinsic and intrinsic apoptosis, these results provided a second line of evidence that caspase activation and thus apoptosis seems not to occur during UCH-L1-mediated death of kidney podocytes.

To address this point in more detail, we directly measured the activity of caspase- 3 and caspase- 8 (as the major initiator caspase activated by death receptors). As shown in Figure 6C, no increase in caspase-3 or caspase-8 activity beyond the already present basal levels was detectable in doxycycline-treated (i.e. UCH-L1-overexpressing, Western Blot in Figure 6C) vs. untreated UCH-L1 tet-on podocytes or vs. negative controls (doxycycline-treated podocytes that are stably transduced with empty vector; tetpodocytes). In contrast, the activity of both caspases was clearly increased in positive control lysates from doxycycline-treated tet- podocytes treated with cytochrome $\mathrm{c}$ and dATP to validate the assay, in summary 

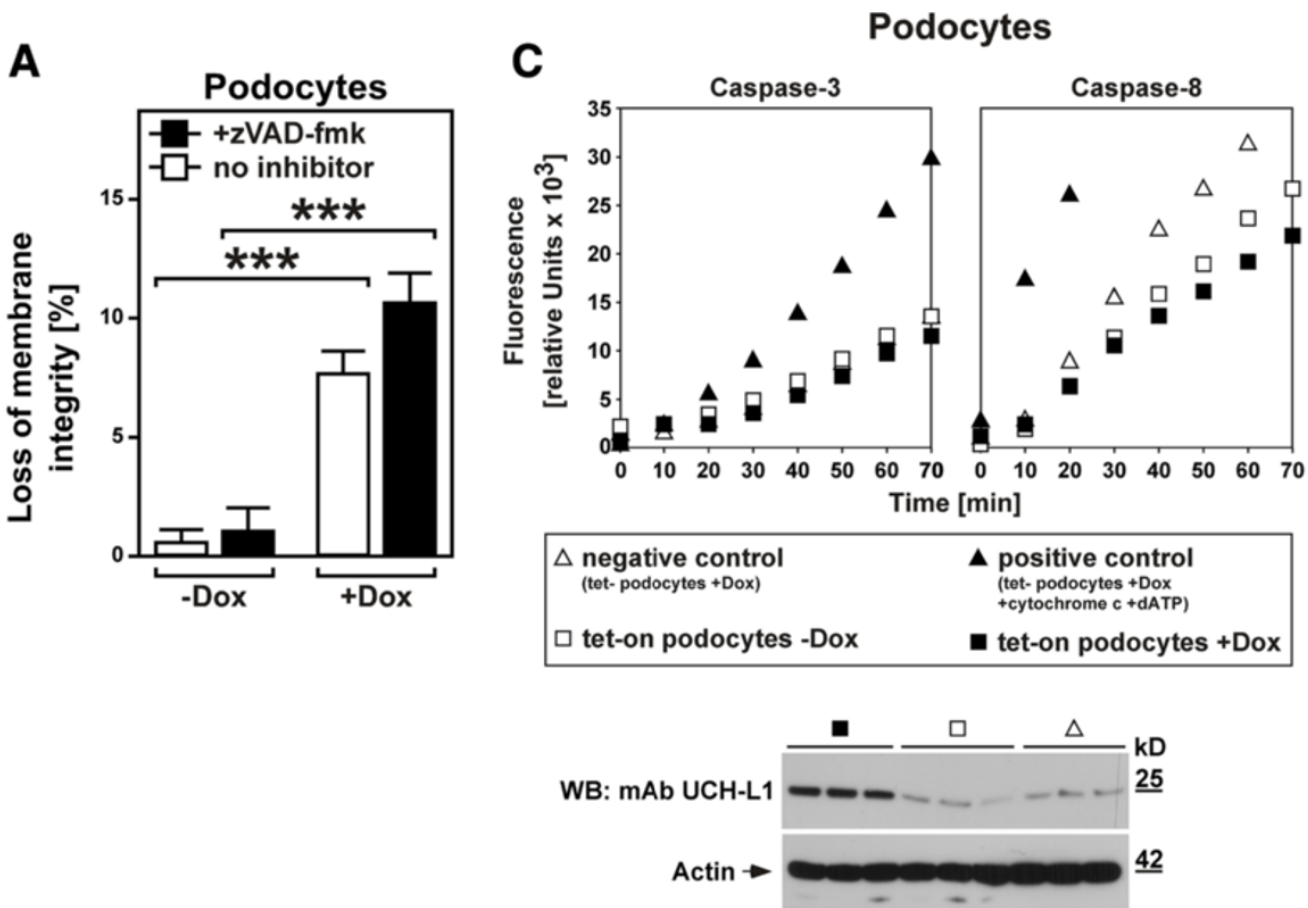

B
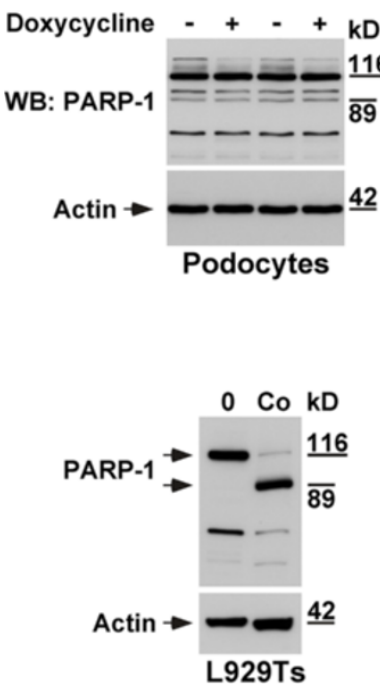

D

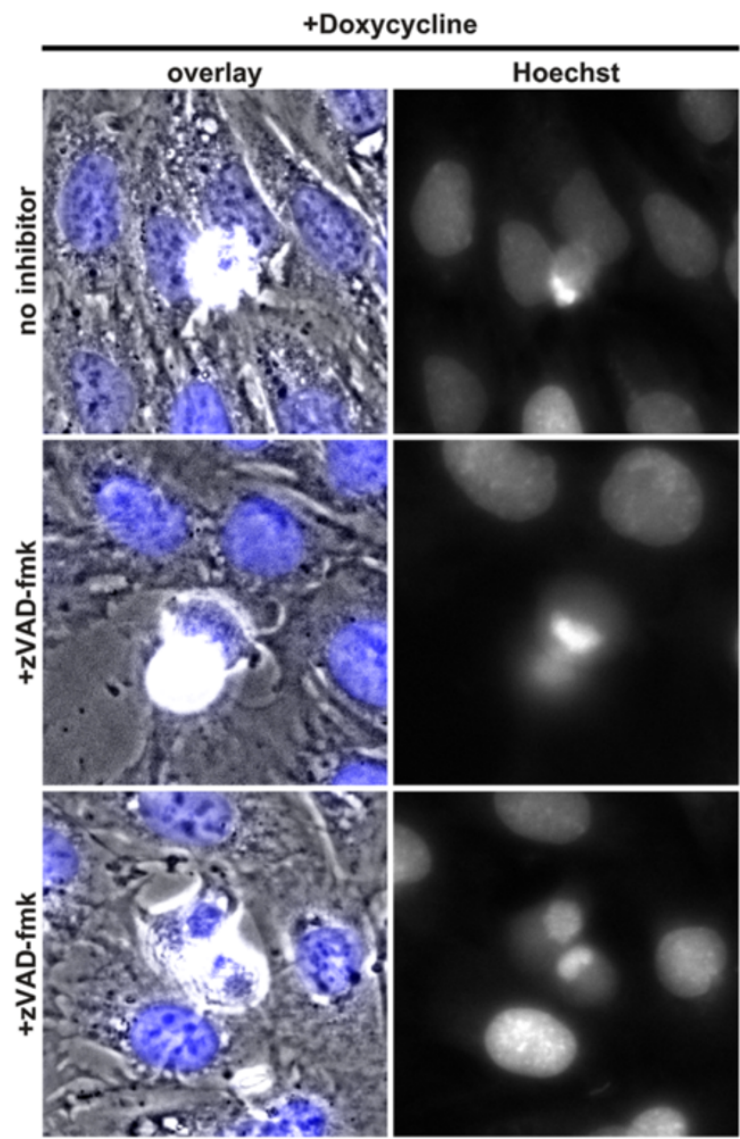




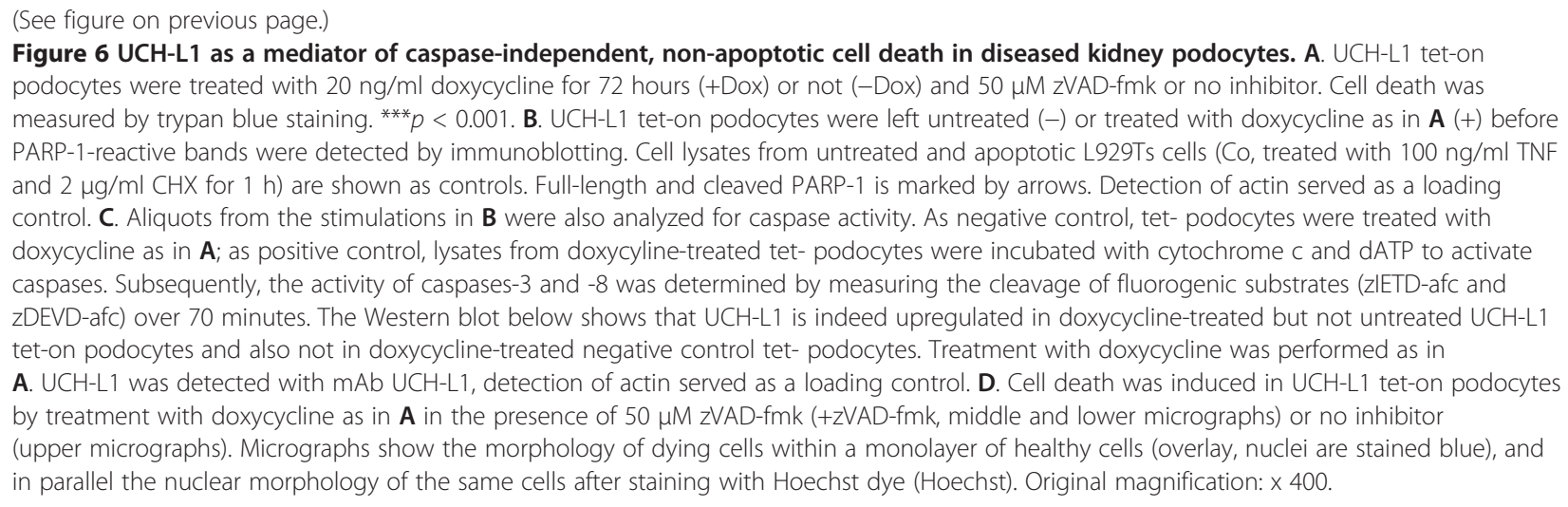

further corroborating the assumption that UCH-L1-mediated death of podocytes occurs without activation of caspases and thus in a non-apoptotic manner.

Finally, when analyzed by microscopy, doxycyclinetreated UCH-L1 tet-on podocytes did not display typical apoptotic changes such as membrane blebbing, type 2 chromatin condensation and accumulation of fragmented chromatin at the nuclear periphery which we had earlier observed for apoptosis in other cell systems [33]. Rather, only an incomplete, lumpy condensation of chromatin was detectable that has previously been associated with programmed necrosis/necroptosis rather than apoptosis [16]. Moreover, and as shown above for cell death, the addition of zVAD-fmk did not affect the changes in the cellular and nuclear morphology of podocytes caused by doxycycline-induced overexpression of UCH-L1 (Figure 6D). Altogether, these results rule out caspase-dependent apoptosis but rather favor caspaseindependent, non-apoptotic forms of cell death such as programmed necrosis or necroptosis as the most probable cause for UCH-L1-mediated podocyte death.

\section{Inhibition of UCH-L1 protects podocytes from TNF-induced necroptosis}

As a central proinflammatory cytokine, TNF may also contribute to inflammatory reactions in the kidney and thus to subsequent podocyte injury. We therefore wanted to determine whether UCH-L1 can act as a mediator of TNF-induced necroptosis not only in L929Ts cells (as shown in Figure 5), but also in podocytes. For this purpose, we analyzed podocytes stably transfected with an shRNA construct that causes permanent knockdown of UCH-L1 or with a scrambled negative control shRNA [30]. As shown in Figure 7, podocytes with stable downregulation of $\mathrm{UCH}-\mathrm{L} 1$ were significantly protected from TNF-induced cell death when compared to control podocytes. Moreover, and identical to podocyte death caused by UCH-L1 overexpression (Figure 6A), the addition of zVAD-fmk did not prevent TNF-induced cell death, demonstrating that TNF indeed elicits necroptosis in podocytes, and that UCH-L1 represents a downstream mediator of the necroptotic signaling cascade of TNF also in podocytes.

\section{Discussion}

The impact of caspase-independent, non-apoptotic PCD such as necroptosis/programmed necrosis has become increasingly clear in the last years. This is particularly true for pathological processes, for example renal [42], cardiac and retinal ischemia/reperfusion injury, hyperacute shock [45], brain damage or pancreatitis [12], Huntington's, Parkinson's and Alzheimer's disease, epilepsy, muscular dystrophy, as well as for the destruction of cells by pathogens such as vaccinia virus, HIV, Shigella and Salmonella $[2,12,46,47]$. The option to therapeutically interfere with necroptosis/programmed necrosis has raised great expectations [12]. In consequence, a better knowledge of the still incompletely understood signaling pathways and the associated components will facilitate future strategies to interfere with damage induced by necroptosis/ programmed necrosis (e.g. in shock, stroke, myocardial infarction or kidney failure). Here, we have identified the proteases HtrA2/Omi and UCH-L1 as two such components of TNF-induced necroptosis, and thus revealed two novel targets for therapeutic intervention, e.g. by future Ucf-101- or LDN57444-derived drugs suited for use in patients.

Based upon the results of our study, we propose the model shown in Figure 8 to integrate $\mathrm{HtrA} 2 / \mathrm{Omi}$ and UCH-L1 into the known signaling pathways of TNFinduced necroptosis. In this model, binding of TNF to TNF-R1 induces activation of the kinases RIPK1, RIPK3, and of MLKL as components of the necrosomal core complex. Notably, we have been unable to detect HtrA2/Omi as part of the necroptotic TNF-R1 signaling complex in preliminary experiments (D. A. and S. S., 


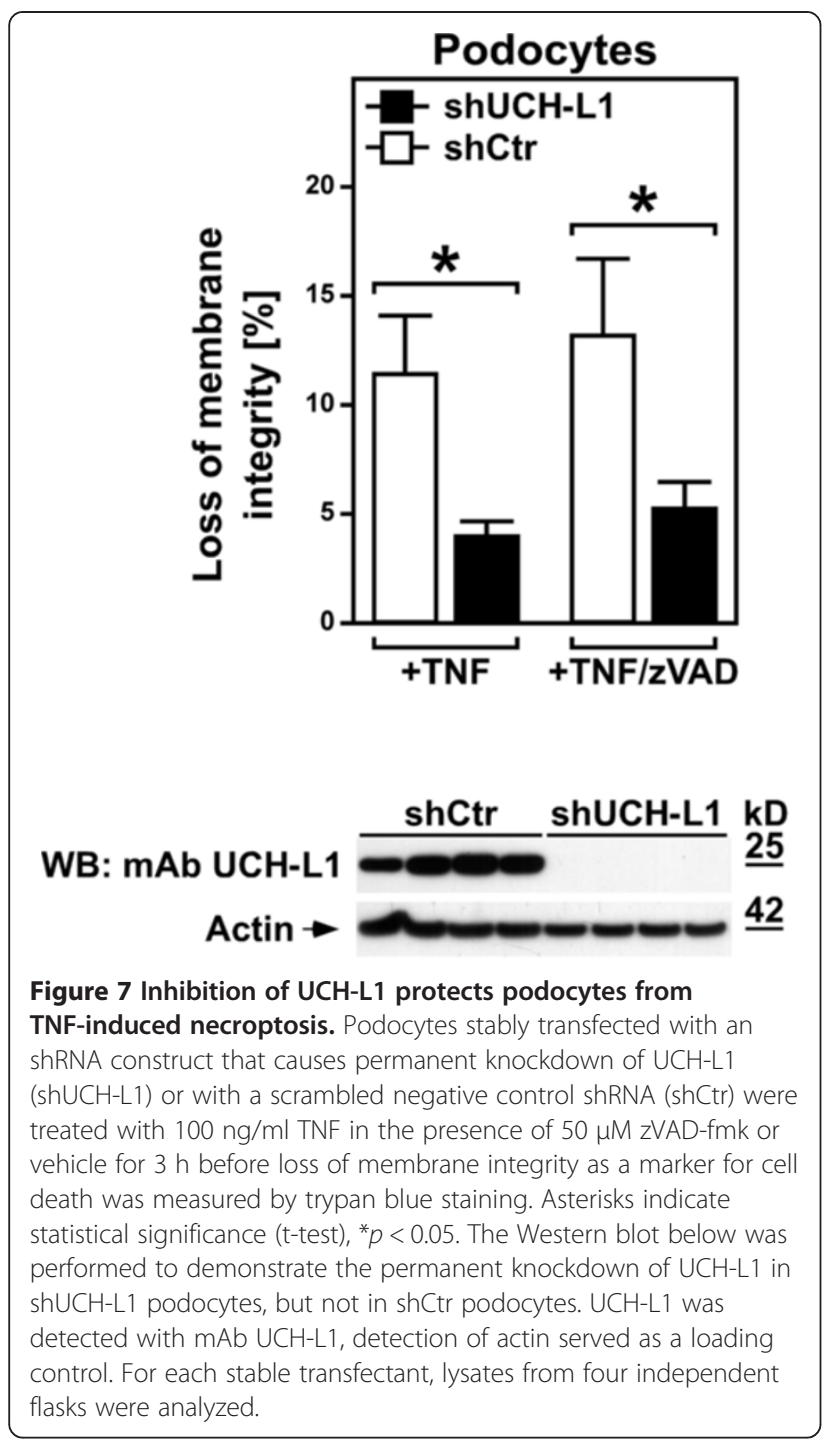

unpublished observations), and no other study has yet reported an association of HtrA2/Omi with components of the TNF-R1 signaling complex during necroptosis. This is also consistent with reports showing that, in contrast to apoptosis, HtrA2/Omi is not released from mitochondria during TNF-induced necroptosis $[23,48]$. In summary, these findings argue against a direct interaction of HtrA2/Omi with RIPK1, RIPK3 or MLKL but instead suggest that $\mathrm{HtrA} 2 / \mathrm{Omi}$ is activated indirectly within the mitochondria. As the most likely mechanism, MLKL has been found to activate the phosphatases PGAM5L/S, which in turn couple to the mitochondrial protein Drp-1, and as a mitochondrial attack complex [11], may cause the subsequent intramitochondrial activation of HtrA2/Omi. Consistent with a function of HtrA2/Omi in TNF-induced necroptosis despite this

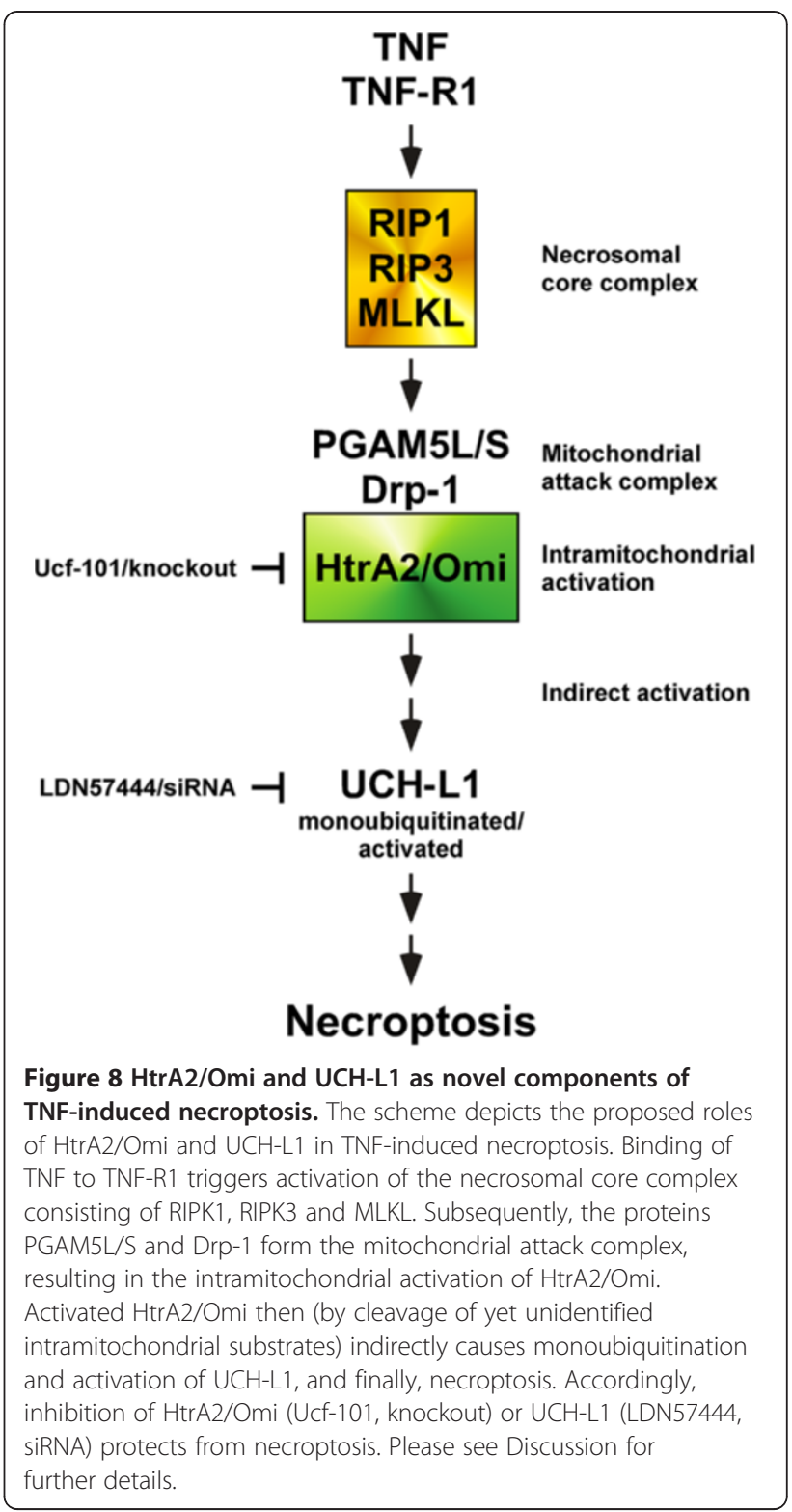

intramitochondrial localization, inhibition of HtrA2/Omi activity by Ucf-101 or by genetic deletion (knockout) blocks the necroptotic signal of TNF (this was similarly observed for Ucf-101 in an independent study in neutrophils, where the authors also concluded that HtrA2/Omi mediates necroptosis through its serine protease properties from within the mitochondria [48]). Downstream of HtrA2/Omi, our data identify UCH-L1 as another, novel component of the signaling cascade. In contrast to staurosporine-induced apoptosis, where HtrA2/Omi translocates into the cytosol and directly cleaves and thus inactivates $\mathrm{UCH}-\mathrm{L} 1$ [38], the intramitochondrial localization of HtrA2/Omi during TNF-induced 
necroptosis prevents a direct interaction of both proteins. Rather, and also explaining why we did not see a direct cleavage (and thus inactivation) of $\mathrm{UCH}-\mathrm{L} 1$ by HtrA2/Omi, HtrA2/Omi seems to act indirectly, by yet unknown mechanism (e.g. cleavage of unidentified intramitochondrial substrates), causing the monoubiquitination and activation of $\mathrm{UCH}-\mathrm{L} 1$, finally resulting in necroptosis (which can accordingly be blocked via LDN57444 or by RNA interference).

As a side note, UCH-L1 belongs to the family of cysteine proteases, and we wondered why the broad-spectrum calpain/cysteine protease inhibitor E-64 did not confer any significant protection from TNF-induced necroptosis in the experiments performed in this study (Figure 1C) or in additional control experiments (D. A., J. S. and S. V., unpublished observations). To the best of our knowledge, inhibition of UCH-L1 by E-64 has also not been shown in any other study. As a possible explanation, UCH-L1 is an "atypical" cysteine protease because its active site is misaligned when compared to productive cysteine proteases [29]. Therefore, a general cysteine protease inhibitor such as E-64 may have only limited impact on the activity of UCH-L1, in contrast to a specific inhibitor such as LDN57444 or to inhibition of UCH-L1 by RNA interference (which clearly protected L929Ts cells or podocytes from TNF-induced necroptosis, Figure 5A-B, Figure 7).

We would also like to point out that HtrA2/Omi and UCH-L1 obviously represent important, but most certainly not the only factors transmitting the necroptotic death signals of TNF downstream of RIPK1/RIPK3/ MLKL. Whereas HtrA2/Omi is expressed ubiquitously [23], the expression of UCH-L1 is restricted to certain tissues $[28,30]$. Therefore, in tissues that do not express $\mathrm{UCH}-\mathrm{L} 1$, necroptosis must be relayed by additional, independent factors. Notably, the brain is an organ where a rapid and efficient apoptotic elimination of cells is dangerous, and where alternative, caspase-independent forms of PCD predominate [16]. The brain is also the organ with the highest expression of UCH-L1 in the entire body [32], suggesting that a deregulation of UCHL1 activity in the brain may contribute to necroptotic damage, e.g. after traumatic injury [31] or after stroke (i.e. ischemia/reperfusion damage). Interestingly, both $\mathrm{UCH}-\mathrm{L} 1$ as well as HtrA2/Omi have been associated with Parkinson's disease, although a connection to necroptosis has not been investigated so far. Moreover, recent studies have found that necroptosis is also the predominant damage mechanism in ischemia/reperfusion damage in the kidney $[42,49]$, in summary indicating that both brain and kidney are organs where therapeutic strategies aiming to interfere with the necroptotic actions of HtrA2/Omi and UCH-L1 may be worthwhile options to consider for the future, e.g. with regard to stroke or kidney failure.

\section{Conclusions}

We have identified the proteases HtrA2/Omi and UCH-L1 as two crucial components of TNF-induced necroptosis, and thus provided evidence that proteolysis is not only critical for the regulation and execution of apoptosis, but also essential for caspase-independent forms of PCD. A model that integrates HtrA2/Omi and UCH-L1 into the known signaling cascades of TNF-mediated necroptosis is shown in Figure 8. With HtrA2/Omi and UCH-L1, we have also revealed two novel targets for therapeutic intervention, which may assist in developing strategies for the treatment of damage induced by necroptosis/programmed necrosis (e.g. in organs such as the kidney and the brain, caused by stroke or kidney failure).

\section{Methods \\ Reagents}

Highly purified human recombinant TNF was provided by BASF Bioresearch (Ludwigshafen, Germany). Benzyloxycarbonyl-Val-Ala-Asp(OMe)-fluoromethylketone (zVAD) was from Bachem (Bubendorf, Switzerland). TPCK, marimastat, benzyloxycarbonyl-Phe-Ala-fluoromethylketone (zFA-fmk) and trans-Epoxysuccinyl-L-leucylamido(4-guanidino)butane (E-64), were purchased from Sigma (Deisenhofen, Germany), necrostatin-1, TAPI-1, GM6001, 5-[5-(2-nitrophenyl)furfurylidine]-1,3-diphenyl-2-thiobarbituric acid (Ucf-101), benzyloxycarbonyl-Phe-Phe-fluoromethylketone (zFF-fmk) and LDN57444 from Merck Millipore (Darmstadt, Germany), and N-[L-3-trans-(propylcarbamoyl)-oxirane-2-carbonyl]-L-Ile-L-Pro methyl ester (CA-074 Me) from Biomol (Hamburg, Germany). Carboxyfluorescein-labeled phenylalanine chloromethyl ketone (FAM-FFCK) was from Immuno Chemistry Technologies (Bloomington, MN, USA). Staurosporine was obtained from Selleckchem (Munich, Germany), Ubiquitin vinyl methyl ester, HA-tag (HaUbVME) from Enzo Life Sciences (Lausen, Switzerland).

\section{Cell culture}

L929Ts is a TRAIL-sensitive L929 subline derived in our laboratory [33]. NIH3T3 cells naturally expressing RIPK3 and therefore sensitive to necroptosis have been previously described [15,50,51]. Jurkat and HT-29 cells were obtained from the American Type Culture Collection (ATCC, Manassas, VA, USA). Jurkat I42 cells were a kind gift from Francis Ka-Ming Chan (Worcester, MA, USA). Immortalized MEF deficient for HtrA2/Omi [24] and their WT counterparts were originally generated by Julian Downward (London, U. K.) and kindly provided by Thomas Langer (Cologne, Germany). Cells were cultivated in DMEM (NIH3T3, MEF), or a mixture of Click's/ RPMI 1640 medium (all other cell lines) supplemented with $10 \% \mathrm{v} / \mathrm{v}$ fetal calf serum and $2 \mathrm{mM}$ glutamine at $37^{\circ} \mathrm{C}$ in a humidified incubator containing $5 \% \mathrm{w} / \mathrm{v} \mathrm{CO}_{2}$. Media 
were additionally supplemented with $1 \mathrm{mM}$ sodium pyruvate (HT-29) and $50 \mu \mathrm{g} / \mathrm{ml}$ each of streptomycin and penicillin. Murine podocytes (a kind gift from K. H. Endlich, Greifswald) were cultured as described [52]. For differentiation, podocytes were cultured for 14 days under nonpermissive conditions $\left(37^{\circ} \mathrm{C}, 7.4 \% \mathrm{w} / \mathrm{v} \mathrm{CO}_{2}\right.$, RPMI 1640 supplemented with $10 \% \mathrm{v} / \mathrm{v}$ fetal calf serum, $10 \mathrm{mM} \mathrm{N}-2$ hydroxyethylpiperazine-N0-2-ethanesulfonic acid, $1 \mathrm{mM}$ sodium pyruvate, $100 \mathrm{U} / \mathrm{ml}$ penicillin, $100 \mathrm{mg} / \mathrm{ml}$ streptomycin).

\section{Flow cytometric analysis of membrane integrity}

Cells were seeded in twelve-well plates at $5 \times 10^{4}$ cells/ well. Following treatment, both detached and adherent cells were collected by centrifugation. The cells were resuspended in PBS/5 mM EDTA containing $2 \mu \mathrm{g} / \mathrm{ml}$ propidium iodide (PI), and the red fluorescence was measured on a FACSCalibur flow cytometer (Becton Dickinson).

\section{Statistical analysis}

$p$ values were calculated using Student's t-test. Statistical significance is denoted by ${ }^{*} p<0.05,{ }^{* * *} p<0.01,{ }^{* * * * *} p<0.001$.

\section{Microscopy}

For documentation of cell morphology, images from unfixed cells were obtained using an Axiovert 10 microscope (Zeiss, Oberkochen, Germany) and a DS-5M-L1 digital sight camera system (Nikon, Düsseldorf, Germany).

\section{D gel electrophoresis, image analysis and spot picking}

The two-dimensional gel electrophoresis was essentially performed as described before [53]. After harvesting, cells were lysed on ice for $10 \mathrm{~min}$ in TNE buffer $(50 \mathrm{mM}$ Tris $\mathrm{pH}$ 8.0, 1\% v/v NP40, $2 \mathrm{mM}$ EDTA) containing $10 \mu \mathrm{g} / \mathrm{ml}$ protease inhibitor cocktail (Roche, Mannheim, Germany). For protein precipitation, trichloroacetic acid (TCA) was added to the protein lysate to a final concentration of $10 \% \mathrm{v} / \mathrm{v}$. The mixture was incubated for $30 \mathrm{~min}$ on ice and centrifuged at $10,000 \times \mathrm{g}$ at $4^{\circ} \mathrm{C}$ for $20 \mathrm{~min}$. The supernatant was removed, ice-cold acetone was added to wash the pellet and the sample was centrifuged as above. After removal of the supernatant, the pellet was air dried and resuspended in lysis buffer ( $\mathrm{pH}$ 8.5) containing $7 \mathrm{M}$ urea, $2 \mathrm{M}$ thiourea, $30 \mathrm{mM}$ Tris, $4 \% \mathrm{w} / \mathrm{v}$ CHAPS. The supernatant containing the solubilized proteins was recovered after centrifugation for $20 \mathrm{~min}$ at $20,000 \times \mathrm{g}$ at $4^{\circ} \mathrm{C}$. A total amount of $250 \mu \mathrm{g}$ of protein was mixed with rehydration buffer ( $7 \mathrm{M}$ urea, $2 \mathrm{M}$ thiourea, $4 \% \mathrm{w} / \mathrm{v}$ CHAPS, $2 \% \mathrm{v} / \mathrm{v}$ immobilized $\mathrm{pH}$ gradient (IPG) buffer $\mathrm{pH} 3-11$ and $2 \% \mathrm{w} / \mathrm{v}$ DTT) and applied by cup-loading onto $24 \mathrm{~cm}$ non-linear $\mathrm{pH}$ 3-11 IPG gel strips for isoelectric focusing (IEF). The second dimension was performed on $26 \times 20 \mathrm{~cm}$ large $12.5 \% \mathrm{w} / \mathrm{v}$ gels after reduction and alkylation using the Ettan DALTsix large vertical electrophoresis system from GE Healthcare (Munich, Germany). The gels were removed from the glass plates, mounted on a non-backed gel frame, and scanned on a Typhoon Trio imager (GE Healthcare) at green fluorescence. Subsequently, the gels were stained overnight with Flamingo Pink (Bio-Rad, Munich, Germany), and scanned again at red fluorescence. The obtained images were analyzed using Image Master 6.0 (GE Healthcare). Selected spots were picked with a $2 \mathrm{~mm}$ picking head. The picked gels were again scanned to verify the correct location of the punched spots.

\section{In-gel tryptic digestion and mass spectrometry}

The punched gel spots were sequentially washed with water, with $50 \mathrm{mM}$ ammonium bicarbonate $(\mathrm{ABC})$ in $50 \% \mathrm{v} / \mathrm{v} \mathrm{MeOH}$, with $70 \% \mathrm{v} / \mathrm{v}$ acetonitrile $(\mathrm{ACN})$, and dehydrated in pure ACN. ACN was evaporated in a SpeedVac centrifuge (ThermoFisher Scientific, Dreieich, Germany), and the dry gel pieces were subjected to in-gel digestion with $100 \mathrm{ng}$ porcine sequencing-grade trypsin (Serva, Heidelberg, Germany) in $25 \mathrm{mM} \mathrm{ABC}$ at $37^{\circ} \mathrm{C}$ overnight. For peptide extraction, $20 \mu \mathrm{l}$ of $0.1 \% \mathrm{v} / \mathrm{v}$ trifluoroacetic acid (TFA) in ACN was added and the samples were sonicated for $15 \mathrm{~min}$. The supernatants were removed and the gel spots were again incubated with $20 \mu \mathrm{l}$ of $0.1 \% \mathrm{v} / \mathrm{v}$ TFA in ACN for $10 \mathrm{~min}$. The supernatants of both steps were combined, dried in a SpeedVac centrifuge, redissolved in $0.8 \mu \mathrm{l}$ MALDI matrix solution $(3.2 \mathrm{mg} / \mathrm{ml}$ $\alpha$-cyanohydroxycinnamic acid (Sigma) in 65\% v/v ACN/ $0.1 \% \mathrm{v} / \mathrm{v}$ TFA), spotted onto 384-well stainless steel MALDI plates and air-dried. Spectra were acquired on an AB SCIEX MALDI-TOF/TOF 5800 (AB SCIEX, Darmstadt, Germany) mass spectrometer in positive ion mode. For MS measurements, 2000 shots were accumulated in the mass range of 800-4000 m/z. Default calibration was performed using the 4700 Proteomics Analyzer Standards Kit, while MS measurements were calibrated internally using trypsin and contaminant peaks (842.509, 2211.105, 2225.120 and 2807.315 Da). Precursor selection for MS/MS analysis was achieved using the 4000 Series Explorer Software (AB SCIEX) with acquisition of the 20 most intense precursors $(\mathrm{S} / \mathrm{N}>20)$, beginning with the strongest first. All MS/MS spectra were acquired with $1 \mathrm{KV}$ collision energy at ambient air (CID medium: 1.25 x 10-6 Torr) using 3000 laser shots. For peptide identification, MALDI-TOF/TOF MS/MS raw files were searched using ABSciex GPS software (Version 3.6, build 332) with the following pre-filter settings: only peaks within a mass range from $60 \mathrm{Da}$ to the precursor mass minus $35 \mathrm{Da}$ and $\mathrm{S} / \mathrm{N}$ ratio above 10 were used. Spectra were searched with Mascot (version 2.2.04, Matrix Science, London, U.K) against the Swissprot database using Mus musculus as a taxonomy filter (15 Feb 2011, 
16345 sequences) and the following parameters: precursor tolerance, 50 ppm; MSMS tol, 0.3 Da; max missed cleavages 2. Oxidation (M) was set as a variable modification, while carbamidiomethylation $(C)$ was set as a fixed modification. Proteins were considered identified when either 2 peptides were identified with a confidence interval $\geq 99 \%$ $(p<0.01)$ or 3 peptides $\geq 95 \%(p<0.05)$.

\section{RNA interference}

The validated siRNA specific for human HtrA2/Omi (ID \# s654), the predesigned siRNAs specific for murine HtrA2/Omi (ID \# s82292, s82292) murine UCH-L1 (ID \# s75710), murine RIPK3 (ID \# s80755) as well as the negative control siRNA (ID \# AM4611) were obtained from Life Technologies, Darmstadt, Germany. L929Ts cells were transfected with 150 pmol siRNA by Amaxa nucleofection (Lonza, Cologne, Germany), using solution $\mathrm{V}$ and program T-20. Jurkat I42 cells were transfected with 30 pmol siRNA and HiPerFect transfection reagent (Qiagen, Hilden, Germany).

\section{Measurement of intracellular ATP levels}

The intracellular ATP content of cells was determined with the Cell Titer Glo Assay Kit (Promega, Mannheim, Germany) following the instructions of the manufacturer.

\section{Immunoblots}

Unless otherwise indicated, cells were harvested after treatment and lysed at $4^{\circ} \mathrm{C}$ in TNE buffer containing $150 \mathrm{mM} \mathrm{NaCl}, 10 \mu \mathrm{g} / \mathrm{ml}$ protease inhibitor cocktail, $1 \mathrm{mM}$ sodium orthovanadate and $5 \mathrm{mM} \mathrm{NaF}$. Identical amounts of cell protein per lane were resolved by electrophoresis on SDS polyacrylamide gels. After electrophoretic transfer to nitrocellulose, reactive proteins were detected using antisera specific for actin (sc-1615, Santa Cruz, Heidelberg, Germany; A1978, Sigma), HtrA2/Omi (ab32092, Abcam, Cambridge, UK), UCH-L1 (rat monoclonal, clone U104, generated as outlined below, or rabbit polyclonal, CL95101, Cedarlane, Burlington, Ontario, Canada), HA (1187423, Roche), PARP-1 (9542, Cell Signaling, Danvers, MA, USA) and the ECL detection kit (GE Healthcare). Equal loading as well as efficiency of transfer was routinely verified for all Western blots by Ponceau $\mathrm{S}$ staining, and by reprobing the membranes for actin.

\section{Generation of monoclonal UCH-L1 antibodies}

Wistar rats were initially immunized intraperitoneally (i.p.) with $100 \mu \mathrm{g}$ of purified UCH-L1 (kindly provided by Gregory A. Petsko, Waltham, MA, USA) in $60 \mu \mathrm{l}$ phosphate buffer saline (PBS) emulsified with $40 \mu \mathrm{l}$ of Gerbu adjuvant MM (Gerbu Biotechnik, Heidelberg, Germany). The rats were boosted i.p. on days 14 and 21 with $50 \mu \mathrm{g}$ of purified protein emulsified with $20 \% \mathrm{v} / \mathrm{v}$ of the adjuvant. The last two doses (50 $\mu \mathrm{g}$ UCH-L1 in PBS) were administered on days 28 and 29 without adjuvant, while the fusion was done on day 30. Spleen cells from immunized animals were collected and fused with Ag8.653 myeloma cells using polyethylene glycol 1500 (Roche). The fused cells were cultured in selection medium (HAT, Sigma) for 10 days and screened by ELISA for anti-UCH-L1 antibodies. Hybridoma clones producing anti-UCH-L1 monoclonal antibodies (mAbs) were then cultivated in serum-free medium and the mAbs were purified using protein $G$ affinity chromatography (GE Healthcare). The isotype of the anti-UCH-L (U104) clone (IgG1, $\lambda$ ) was determined by using ELISA rat $\mathrm{mAb}$ isotyping kit (ThermoFisher).

\section{Immunoprecipitations}

Cellular lysates were precleared with GammaBind Gsepharose (GE Healthcare) and immunoprecipitation was performed over night on ice using anti-ubiquitin IgG1 monoclonal antibody (MAB1510, Merck Millipore, 1:100 dilution). After collection of the immunecomplexes with GammaBind G-sepharose and three washing steps in lysis buffer, the immunoprecipitated proteins were analyzed by SDS-PAGE and Western blot.

\section{Generation of stably transfected podocytes with inducible overexpression or downregulation of UCH-L1}

For inducible overexpression of UCH-L1, the Retro-X Tet-On Advanced Inducible Expression System (Clontech, Mountain View, CA, USA) was used according to the manufacturers' instructions. Briefly, wildtype murine $\mathrm{UCH}-\mathrm{L} 1$ was amplified by polymerase chain reaction from murine podocytes using the following primers: mUCHL1pRetro-fw 5'CTAGGCGGCCGCGCCACCATGCAGCT GAAGCCGATGGA'3; mUCHL1-pRetro-rev 5'CTAGAC GCGTTTAAGCTGCTTTGCAGAGAG'3 and subsequently cloned into the multiple cloning site of the pRetroX-Tight-Pur vector using NotI and MluI (ThermoFisher). The sequence of UCH-L1 was verified by sequencing (Eurofins MWG Operon, Ebersberg, Germany). For virus production, phoenix ecotropic packaging cells were transfected using $\mathrm{DNA} / \mathrm{CaCl}_{2}$ precipitation with the pRetroX-Tet-On Advanced vector, with the pRetroXTight-Pur-UCH-L1 vector or the pRetroX-TightPur empty vector as a control, respectively. The virus-containing supernatant of the pRetroX-Tet-On transfected phoenix cells was transferred to a $10 \mathrm{~cm}$ plate containing podocyte target cells at around 50\% to $60 \%$ confluence; the infection steps were repeated twice. Selection for integration of the pRetroX-Tet-On Advanced expression plasmid was performed with G418 (500 $\mu \mathrm{g} / \mathrm{ml}$, Life Technologies) for 7 days. Afterwards, the virus-containing supernatant of the pRetroX-Tight-Pur-UCH-L1 transfected phoenix cells was transferred to the pRetroX-Tet-On Advanced transduced 
podocyte target cells; the infection steps were again repeated twice. Selection for integration of the pRetroXTight-Pur-UCH-L1 plasmid was performed with puromycin $(1.5 \mu \mathrm{g} / \mathrm{ml}$, Sigma). For negative control experiments, the pRetroX-Tight-Pur vector was transduced without insert (tet-) into the pRetroX-Tet-On Advanced expressing podocytes. For induction of UCH-L1 overexpression, UCH-L1 tet-on or tet- podocytes were cultured in the presence of tetracycline free medium (PANBiotech, Aidenbach, Germany) supplemented with $20 \mathrm{ng} / \mathrm{ml}$ doxycycline or without doxycycline for control. For stable knockdown experiments, shRNA627 to murine UCH-L1 or scrambled shRNA for control was overexpressed in podocytes as described before [30].

\section{Analysis of caspase activity, cell death, and cellular and nuclear morphology in podocytes}

$10^{5}$ differentiated UCH-L1 tet-on or tet- podocytes were plated in 6-well plates in tetracycline-free RPMI 1640 medium (Life Technologies) supplemented with $10 \% \mathrm{v} / \mathrm{v}$ fetal calf serum, $10 \mathrm{mM} \mathrm{N}$-2-hydroxyethylpiperazine-NO2-ethanesulfonic acid, $1 \mathrm{mM}$ sodium pyruvate, $100 \mathrm{U} / \mathrm{ml}$ penicillin and $100 \mathrm{mg} / \mathrm{ml}$ streptomycin. UCH-L1 overexpression was induced with $20 \mathrm{ng} / \mathrm{ml}$ doxycycline for 72 hours or not. For measurements of caspase activity, cells were collected and lysed in a buffer containing $10 \mathrm{mM}$ Hepes pH 7.4, $142 \mathrm{mM} \mathrm{KCl}, 5 \mathrm{mM} \mathrm{MgCl} 2,1 \mathrm{mM}$ EGTA, $0.2 \% \mathrm{v} / \mathrm{v}$ NP40, $1 \mathrm{mM}$ DTT and $2 \mathrm{mM}$ Pefabloc (Roche). To generate positive controls, $20 \mu \mathrm{g}$ of cells lysate were equilibrated for $1 \mathrm{~h}$ at $30^{\circ} \mathrm{C}$ after the addition of $1 \mathrm{mM}$ dATP and $10 \mu \mathrm{M}$ cytochrome $\mathrm{c}$ to permit activation of caspases. Subsequently, $100 \mu \mathrm{l}$ of caspase buffer (20 mM Pipes, $100 \mathrm{mM} \mathrm{NaCl}, 10 \mathrm{mM}$ DTT, 1 mM EDTA, $0.1 \% \mathrm{w} / \mathrm{v}$ CHAPS, $10 \% \mathrm{w} / \mathrm{v}$ sucrose, $\mathrm{pH}$ 7.2) containing $100 \mu \mathrm{M}$ zDEVD-afc (benzyloxycarbonyl-Asp(OMe)-Glu (OMe)-Val-DL-Asp(OMe)-7-aminotrifluoromethylcoumarin, Merck Millipore) or zIETD-afc benzyloxycarbonylIle-Glu(OMe)-Thr-DL-Asp(OMe)-7-aminotrifluoromethyl coumarin (Merck Millipore) were added to $10 \mu \mathrm{l}$ of cytosolic extract $\left(10 \mu \mathrm{g}\right.$ protein) and incubated at $37^{\circ} \mathrm{C}$. The release of afc was measured as emission at $505 \mathrm{~nm}$ upon excitation at $405 \mathrm{~nm}$ using an Infinite M200 fluorimeter equipped with a thermostated plate reader (Tecan, Crailsheim, Germany). For measurements of podocyte death, viable and dead cells were detached with trypsin and counted in a Neubauer chamber after $0.1 \% \mathrm{w} / \mathrm{v}$ trypan blue (Life Technologies) staining. The percentage of dead cells was calculated and plotted as mean $+/-$ SEM, $\mathrm{n}=12$ per condition. To analyze cellular and nuclear morphology, cells were stained with Hoechst dye $(10 \mu \mathrm{g} / \mathrm{ml}$, Life Technologies) for $5 \mathrm{~min}$ and DNA condensation in UCH-L1 tet-on podocytes with or without induced UCH-L1 overexpression for 72 hours was evaluated under an Axio Observer A1 microscope (Zeiss) using the axiovision software (Zeiss).

\section{Analysis of TNF-induced cell death in podocytes}

Differentiated sh627 and scrambled shRNA control podocytes were plated at a density of $10^{4}$ cells per 6-well plate. After 48 hours, cells were treated with $100 \mathrm{ng} / \mathrm{ml}$ murine TNF (PeproTech, Hamburg, Germany) with addition of $50 \mu \mathrm{M}$ zVAD-fmk or vehicle (ethanol) as control for 3 hours. Cells were detached with trypsin and the amount of dead and living cells was counted in a Neubauer chamber following staining with $0.1 \%$ w/v trypan blue. The percentage of dead cells was calculated and plotted as mean $+/-$ SEM, $\mathrm{n}=12$ per condition.

\section{Competing interests}

The authors declare that they have no competing interests.

\section{Authors' contributions}

JS, SV, DK, OJ, CMS, SS and DA designed research; JS, SV, SM, AT and CMS performed research; JS, SV, DK, AT, OJ, CMS, SS and DA analyzed data, DA wrote the manuscript. All authors read and approved the final manuscript.

\section{Acknowledgements}

We thank Parvin Davarnia for excellent technical assistance, Melanie Nebendahl for help with 2D gel electrophoresis, and the Z2-project of the SFB 877 (Bart van den Berg, Tomas Koudelka and Andreas Tholey) for performing mass spectrometry and protein identification. This work was supported by grants from the Deutsche Forschungsgemeinschaft (SFB 877, project B2, to D. A. and S. S., and projects Z2, Z3) and by a fellowship from the German Academic Exchange Service (DAAD, A/08/79433, to J. S.).

\section{Author details}

${ }^{1}$ Institut für Immunologie, Christian-Albrechts-Universität zu Kiel, Michaelisstr. 5, 24105 Kiel, Germany. ${ }^{2}$ Biochemisches Institut, Christian-Albrechts-Universität zu Kiel, Olshausenstr. 40, 24098 Kiel, Germany. ${ }^{3}$ Zentrum für Innere Medizin, Nephrologie, Universitätsklinikum Hamburg-Eppendorf, Martinistr. 52, 20246 Hamburg, Germany.

Received: 19 July 2013 Accepted: 1 October 2013

Published: 3 October 2013

References

1. Degterev A, Yuan J: Expansion and evolution of cell death programmes. Nat Rev Mol Cell Biol 2008, 9:378-390.

2. Festjens N, Vanden Berghe T, Vandenabeele P: Necrosis, a well-orchestrated form of cell demise: signalling cascades, important mediators and concomitant immune response. Biochim Biophys Acta 2006, 1757:1371-1387.

3. Mocarski ES, Upton JW, Kaiser WJ: Viral infection and the evolution of caspase 8-regulated apoptotic and necrotic death pathways. Nat Rev Immunol 2012, 12:79-88.

4. Han J, Zhong CQ, Zhang DW: Programmed necrosis: backup to and competitor with apoptosis in the immune system. Nat Immunol 2011, 12:1143-1149.

5. Ch'en IL, Tsau JS, Molkentin JD, Komatsu M, Hedrick SM: Mechanisms of necroptosis in T cells. J Exp Med 2011, 208:633-641.

6. Chavez-Valdez R, Martin LJ, Northington FJ: Programmed necrosis: a prominent mechanism of cell death following neonatal brain injury. Neurol Res Int 2012, 2012:257563.

7. Dorn GW 2nd: Molecular mechanisms that differentiate apoptosis from programmed necrosis. Toxicol Pathol 2013, 41:227-234.

8. Declercq W, Takahashi N, Vandenabeele P: Dual face apoptotic machinery: from initiator of apoptosis to guardian of necroptosis. Immunity 2011, 35:493-495 
9. Kaczmarek A, Vandenabeele P, Krysko DV: Necroptosis: the release of damage-associated molecular patterns and its physiological relevance. Immunity 2013, 38:209-223.

10. Kang TB, Yang SH, Toth B, Kovalenko A, Wallach D: Caspase-8 blocks kinase RIPK3-mediated activation of the NLRP3 inflammasome. Immunity 2013, 38:27-40.

11. Chan FK, Baehrecke EH: RIP3 finds partners in crime. Cell 2012, 148:17-18.

12. Vandenabeele P, Galluzzi L, Vanden Berghe T, Kroemer G: Molecular mechanisms of necroptosis: an ordered cellular explosion. Nat Rev Mol Cell Biol 2010, 11:700-714.

13. Strelow A, Bernardo K, Adam-Klages S, Linke T, Sandhoff K, Krönke M, Adam D: Overexpression of acid ceramidase protects from tumor necrosis factor-induced cell death. J Exp Med 2000, 192:601-611.

14. Thon L, Möhlig H, Mathieu S, Lange A, Bulanova E, Winoto-Morbach S, Schütze S, Bulfone-Paus S, Adam D: Ceramide mediates caspase-independent programmed cell death. FASEB J 2005, 19:1945-1956.

15. Sosna J, Voigt S, Mathieu S, Lange A, Thon L, Davarnia P, Herdegen T, Linkermann A, Rittger A, Chan FK, et al: TNF-induced necroptosis and PARP-1-mediated necrosis represent distinct routes to programmed necrotic cell death. Cell Mol Life Sci 2013. epub ahead of print, doi: 10.1007/s00018-013-1381-6.

16. Leist $M$, Jäättelä M: Four deaths and a funeral: from caspases to alternative mechanisms. Nat Rev Mol Cell Biol 2001, 2:589-598.

17. Bröker LE, Kruyt FA, Giaccone G: Cell death independent of caspases: a review. Clin Cancer Res 2005, 11:3155-3162.

18. Mansat V, Bettaieb A, Levade T, Laurent G, Jaffrezou JP: Serine protease inhibitors block neutral sphingomyelinase activation, ceramide generation, and apoptosis triggered by daunorubicin. FASEB J 1997, 11:695-702.

19. Dünstl G, Weiland T, Schlaeger C, Nüssler A, Künstle G, Wendel A: Activation of an alternative death receptor-induced signaling pathway in human hepatocytes under caspase arrest. Arch Biochem Biophys 2007, 462:140-149.

20. Egger L, Schneider J, Rhême C, Tapernoux M, Häcki J, Borner C: Serine proteases mediate apoptosis-like cell death and phagocytosis under caspase-inhibiting conditions. Cell Death Differ 2003, 10:1188-1203.

21. Vercammen D, Vandenabeele P, Beyaert R, Declercq W, Fiers W: Tumour necrosis factor-induced necrosis versus anti-Fas-induced apoptosis in L929 cells. Cytokine 1997, 9:801-808.

22. Robertson JD, Zhivotovsky B: New methodology is a key to progress. Cell Cycle 2002, 1:119-121.

23. van Loo G, van Gurp M, Depuydt B, Srinivasula SM, Rodriguez I, Alnemri ES, Gevaert K, Vandekerckhove J, Declercq W, Vandenabeele P: The serine protease $\mathrm{Omi} / \mathrm{HtrA} 2$ is released from mitochondria during apoptosis. Omi interacts with caspase-inhibitor XIAP and induces enhanced caspase activity. Cell Death Differ 2002, 9:20-26.

24. Martins LM, Morrison A, Klupsch K, Fedele V, Moisoi N, Teismann P, Abuin A, Grau E, Geppert M, Livi GP, et al: Neuroprotective role of the Reaper-related serine protease $\mathrm{Htr}$ 2/Omi revealed by targeted deletion in mice. Mol Cell Biol 2004, 24:9848-9862.

25. Vande Walle L, Wirawan E, Lamkanfi M, Festjens N, Verspurten J, Saelens X, Vanden Berghe T, Vandenabeele $P$ : The mitochondrial serine protease HtrA2/Omi cleaves RIP1 during apoptosis of Ba/F3 cells induced by growth factor withdrawal. Cell Res 2010, 20:421-433.

26. Okada M, Adachi S, Imai T, Watanabe K, Toyokuni SY, Ueno M, Zervos AS, Kroemer G, Nakahata T: A novel mechanism for imatinib mesylate-induced cell death of BCR-ABL-positive human leukemic cells: caspase-independent, necrosis-like programmed cell death mediated by serine protease activity. Blood 2004, 103:2299-2307.

27. McCormick AL, Roback L, Mocarski ES: HtrA2/Omi terminates cytomegalovirus infection and is controlled by the viral mitochondrial inhibitor of apoptosis (vMIA). PLOS Pathog 2008, 4:e1000063.

28. Meyer-Schwesinger C, Meyer TN, Münster S, Klug P, Saleem M, Helmchen U, Stahl RAK: A new role for the neuronal ubiquitin C-terminal hydrolase-L1 (UCH-L1) in podocyte process formation and podocyte injury in human glomerulopathies. J Pathol 2009, 217:452-464.

29. Boudreaux DA, Maiti TK, Davies CW, Das C: Ubiquitin vinyl methyl ester binding orients the misaligned active site of the ubiquitin hydrolase UCHL1 into productive conformation. Proc Natl Acad Sci USA 2010 107:9117-9122.
30. Meyer-Schwesinger C, Meyer TN, Sievert H, Hoxha E, Sachs M, Klupp EM, Münster S, Balabanov S, Carrier L, Helmchen U, et al: Ubiquitin C-terminal hydrolase-I1 activity induces polyubiquitin accumulation in podocytes and increases proteinuria in rat membranous nephropathy. Am J Pathol 2011, 178:2044-2057.

31. Zhang H, Sun Y, Hu R, Luo W, Mao X, Zhao Z, Chen Q, Zhang Z: The regulation of the UCH-L1 gene by transcription factor NF-kappaB in podocytes. Cell Signal 2013, 25:1574-1585.

32. Cartier AE, Djakovic SN, Salehi A, Wilson SM, Masliah E, Patrick GN: Regulation of synaptic structure by ubiquitin C-terminal hydrolase L1. J Neurosci 2009, 29:7857-7868.

33. Thon L, Mathieu S, Kabelitz D, Adam D: The murine TRAIL receptor signals caspase-independent cell death through ceramide. Exp Cell Res 2006, 312:3808-3821.

34. He S, Wang L, Miao L, Wang T, Du F, Zhao L, Wang X: Receptor interacting protein kinase-3 determines cellular necrotic response to TNF-alpha. Cell 2009, 137:1100-1111.

35. Egger L, Madden DT, Rhême C, Rao RV, Bredesen DE: Endoplasmic reticulum stress-induced cell death mediated by the proteasome. Cell Death Differ 2007, 14:1172-1180.

36. Cilenti $L$, Lee $Y$, Hess $S$, Srinivasula $S$, Park KM, Junqueira D, Davis H, Bonventre JV, Alnemri ES, Zervos AS: Characterization of a novel and specific inhibitor for the pro-apoptotic protease Omi/HtrA2. J Biol Chem 2003, 278:11489-11494.

37. Chan FKM, Shisler J, Bixby JG, Felices M, Zheng L, Appel M, Orenstein J, Moss B, Lenardo MJ: A role for tumor necrosis factor receptor-2 and receptor-interacting protein in programmed necrosis and antiviral responses. J Biol Chem 2003, 278:51613-51621.

38. Park DW, Nam MK, Rhim H: The serine protease HtrA2 cleaves UCH-L1 and inhibits its hydrolase activity: implication in the UCH-L1-mediated cell death. Biochem Biophys Res Commun 2011, 415:24-29.

39. Meray RK, Lansbury PT Jr: Reversible monoubiquitination regulates the Parkinson disease-associated ubiquitin hydrolase UCH-L1. J Biol Chem 2007, 282:10567-10575.

40. Liu Y, Lashuel HA, Choi S, Xing X, Case A, Ni J, Yeh LA, Cuny GD, Stein RL, Lansbury PT Jr: Discovery of inhibitors that elucidate the role of UCH-L1 activity in the $\mathrm{H} 1299$ lung cancer cell line. Chem Biol 2003, 10:837-846.

41. Tharaux PL, Huber TB: How many ways can a podocyte die? Semin Nephrol 2012, 32:394-404.

42. Linkermann A, Bräsen JH, Himmerkus N, Liu S, Huber TB, Kunzendorf U, Krautwald S: Rip1 (receptor-interacting protein kinase 1) mediates necroptosis and contributes to renal ischemia/reperfusion injury. Kidney Int 2012, 81:751-761.

43. Vercammen D, Beyaert R, Denecker G, Goossens V, van Loo G, Declercq W, Grooten J, Fiers W, Vandenabeele P: Inhibition of caspases increases the sensitivity of L929 cells to necrosis mediated by tumor necrosis factor. J Exp Med 1998, 187:1477-1485.

44. Lazebnik YA, Kaufmann SH, Desnoyers S, Poirier GG, Earnshaw WC Cleavage of poly(ADP-ribose) polymerase by a proteinase with properties like ICE. Nature 1994, 371:346-347.

45. Cauwels A, Janssen B, Waeytens A, Cuvelier C, Brouckaert P: Caspase inhibition causes hyperacute tumor necrosis factor-induced shock via oxidative stress and phospholipase A2. Nat Immunol 2003, 4:387-393.

46. Millay DP, Sargent MA, Osinska H, Baines CP, Barton ER, Vuagniaux G Sweeney HL, Robbins J, Molkentin JD: Genetic and pharmacologic inhibition of mitochondrial-dependent necrosis attenuates muscular dystrophy. Nat Med 2008, 14:442-447

47. Cho YS, Challa S, Moquin D, Genga R, Ray TD, Guildford M, Chan FK: Phosphorylation-driven assembly of the RIP1-RIP3 complex regulates programmed necrosis and virus-induced inflammation. Cell 2009, 137:1112-1123.

48. Blink E, Maianski NA, Alnemri ES, Zervos AS, Roos D, Kuijpers TW: Intramitochondrial serine protease activity of Omi/HtrA2 is required for caspase-independent cell death of human neutrophils. Cell Death Differ 2004, 11:937-939.

49. Linkermann A, Bräsen JH, Darding M, Jin MK, Sanz AB, Heller JO, De Zen F, Weinlich R, Ortiz A, Walczak H, et al: Two independent pathways of regulated necrosis mediate ischemia-reperfusion injury. Proc Natl Acad Sci USA 2013, 110:12024-12029. 
50. Zhang DW, Shao J, Lin J, Zhang N, Lu BJ, Lin SC, Dong MQ, Han J: RIP3, an energy metabolism regulator that switches TNF-induced cell death from apoptosis to necrosis. Science 2009, 325:332-336.

51. Lüschen S, Ussat S, Scherer G, Kabelitz D, Adam-Klages S: Sensitization to death receptor cytotoxicity by inhibition of Fas-associated death domain protein (FADD)/caspase signaling - Requirement of cell cycle progression. J Biol Chem 2000, 275:24670-24678.

52. Schiwek D, Endlich N, Holzman L, Holthöfer H, Kriz W, Endlich K: Stable expression of nephrin and localization to cell-cell contacts in novel murine podocyte cell lines. Kidney Int 2004, 66:91-101.

53. Schmidt H, Gelhaus C, Lucius R, Nebendahl M, Leippe M, Janssen O: Enrichment and analysis of secretory lysosomes from lymphocyte populations. BMC Immunol 2009, 10:41.

doi:10.1186/1478-811X-11-76

Cite this article as: Sosna et al:: The proteases HtrA2/Omi and UCH-L1 regulate TNF-induced necroptosis. Cell Communication and Signaling $201311: 76$

\section{Submit your next manuscript to BioMed Central and take full advantage of:}

- Convenient online submission

- Thorough peer review

- No space constraints or color figure charges

- Immediate publication on acceptance

- Inclusion in PubMed, CAS, Scopus and Google Scholar

- Research which is freely available for redistribution 